Chapter 36

\title{
Exercise Therapy - Additional Tool for Managing Physical and Psychological Problems on Hemodialysis
}

\author{
Andrea Mahrova and Klara Svagrova \\ Additional information is available at the end of the chapter \\ http://dx.doi.org/10.5772/53058
}

\section{Introduction}

Chronic renal failure (CRF) is a progressive and untreatable disease which is associated with numerous complex metabolic and hormonal changes leading to a development of consequent complications which further change function of all organ systems [1]. CRF has several stages. The last one is known as the end-stage renal disease (ESRD). The renal function at this stage has to be replaced by either hemodialysis (HD) or peritoneal dialysis (PD). Such treatment is a life saving method but it does not completely substitute function of healthy kidney [2]. Therefore the best solution for all patients is kidney transplantation. Certain level of physical fitness of all patients on the waiting list for the transplantation is necessary for both successful transplant surgery as well as high quality of life (QoL) with the transplanted kidney. Long-term inactivity prior the kidney transplantation and most importantly during the dialysis treatment leads to diminished physical fitness of dialysis patients who most often suffer from muscular atrophy, low capacity of musculoskeletal system, bone and joint diseases, or system nervous malfunctions [3].

ESRD patients often suffer from other diseases. Associated lifestyle changes typically affect motor and cardiovascular systems. Complications associated with deterioration of those systems have negative impact on the renal disease itself and consequently results in diminished QoL. In fact HD patients' mortality is caused by cardiovascular diseases from $50 \%$ (atherosclerosis, ischemic heart disease, and hypertension) [4-7].

Physical load is less tolerated by HD patients as the disease progresses without the influence of the renal disease type [8]. Deligiannis [7] and Kouidi [9] found that patients with CRF have maximal oxygen consumption decreased by $50 \%$ as compared to healthy but sedentary population. Complications associated with motor system include bone, joint, and muscular problems caused by renal osteodystrophy which is typical for long-term CRF patients. Other 
complications typical for CRF patients and dialysis treatment include anemia, diabetes mellitus, lipid and protein metabolic disorders, uremic myopathy and neuropathy, malnutrition, or all cause peripheral neuropathy [10, 11, 12]. Long-term HD patients often suffer from peripheral vascular disease, dialysis amyloidosis, cerebrovascular complications, immunodeficiency, infections, malignant diseases, etc. [2]. All those complications limit patients' physical fitness and occupational capacity [7, 13]. Decreased physical activity is characterized by functional failures of motor system (back pain, spinal blocks, joint pain) and is associated with limited joint range, muscular shortages, decreased muscular power and endurance, stability disorders, gait changes, or coordination failures $[14,15,16]$. Also one of the most frequent disturbing symptoms of HD patients is pain [17-20]. As a result of above mentioned complications HD patients prefer sedentary lifestyle. Most of those complications and its relationship with physical activity will be described in detail in the following chapters.

Both age of HD patients as well as their quality of life has been improved by a modern technology of dialysis treatment however it is still not comparable with healthy population [21]. HD patients are stressed by a burden of a life threat by untreatable condition typical for patients with chronic conditions such as CRF. In addition HD patients must respect strict dialysis regime (dialysis procedure $2-3$ times per week for $4-5$ hours). Therefore HD patients often suffer from anxiety, inferiority, and depression $[3,22,23]$.

Despite variety of causes leading to limited physical activity of HD patients we have a reason to conclude that earlier mentioned restrictions can be positively influenced by appropriate physical activity. International literature provides evidence that regular physical activity may effectively improve overall status of HD patients (in detail later). Regular physical activity is crucial component of active lifestyle not only among healthy population but also among those with chronic conditions. Certain volume and intensity of physical activity is an effective tool to improve QoL among chronically ill patients and should be a vital part of non-pharmacological complex treatment. Physical activity is currently considered a common part of multidisciplinary approach that consist except for medical treatment also consultations with dietologist, psychologist, and sometimes even social worker. However services of physiotherapists who could propose appropriate physical activity programs for patient on dialysis are still rather rare. Physical activity - passive or active - defined by volume, intensity, and content represents subsequent treatment. Important is also its psychosocial effect which can positively influence performance of everyday tasks by increased selfconfidence, assertive behavior, clear thinking, ability to deal with problems and with the disease, etc. [24].

The goal of this chapter is to emphasize meaning of physical activity among patients on dialysis. The key benefit of regular physical activity in HD patients is to maintain self supported life and independence that is especially important for the elderly patients. The chapter is focused on the description of selected factors influencing physical and mental fitness and presents various ways of appropriate itradialytic and interdialytic physical exercises. In addition it includes description of physical activity programs developed to improve fitness status before and after kidney transplantation. 


\section{Body}

\subsection{Problem statement}

The issues of physical activity programs realization and its influence on quality of life among ESRD patients on dialysis is still discussed topic. In the past 40 years it has been conducted many trials focused on testing the effects of physical fitness among ESRD patients on dialysis, and describing overall benefits of regular physical activity on fitness and mental status [25-47]. The goal of all studies was to offer patients with the interest to include physical activity into daily routines an appropriate fitness program that can be performed during hemodialysis as well as in their free time. Offered programs included both individual and group conditioning exercises.

During the evaluation of the effect of activity programs it has been found that the exercise was a brand new experience for most of the patients and that it was often perceived as a motivating factor to maintain physically active even between dialysis procedures [33, 40, 48, 49]. Although the attendance rate of physical activity programs was found somewhat lower in the classes offered between the dialysis. Also early termination was more often observed in the interdialysis classes [48, 50-52]. The most common causes of the early termination included problems with transportation to the classes, lack of free time between dialysis procedures, lack of motivation, and fatigue. Organized physical activity represents for the majority of patients the only chance to perform regular physical activity. Also organized physical activity is known to be more motivating, guarantees expert supervision and heart functions monitoring. There are number of studies conducted to evaluate a use of individual physiotherapy interventions for those with motor system disorders due to dialysis and after kidney transplantation [14,53-58]. Those studies provided clear evidence that the role of the physiotherapist is absolutely crucial in the multidisciplinary care team working with HD patients. The goal of physiotherapy tailored to HD patients' needs is to optimize physical fitness necessary for safe and long-life mobility and independence with the effort to eliminate dependence on the others for as long as possible [55]. It is important to emphasize substantial financial savings associated with more independent living caused by adequate physical fitness and with a reduction of the use of pharmacotherapy due to decreased blood pressure. According to Miller [59] a year savings of one HD patient can reach 885 USD only for pharmacotherapy expenses.

\subsection{Application area}

As mentioned earlier ESRD patients on dialysis cannot tolerate physical load as effectively as healthy population. Actually the toleration is decreased by $50 \%$. Also they experience lower muscular power, motor system failures, etc. This all together leads to preferred sedentary behavior which was supported by many research studies published in the past 20 years $[3,7-9,21,36,40-47,49,55,59-61]$.

This chapter is focused on the description of selected factors (complications) associated with ESRD and renal dialysis treatment (RDT), especially those affecting physical fitness of HD 
patients. Special attention is paid to motor system disorders. Its symptoms negatively impact patients' abilities and are often accompanied by the first signs of polymorbidity. Yet many conditions can be effectively treated in its early stages by for example regular physical activity which consists of both active and passive techniques.

There is also a huge area dealing with quality of life of ESRD patient. The problematic will be discussed only briefly although it would deserve whole chapter.

Most of the health complications associated with the ESRD and the dialysis treatment do not allow medical personnel to focus attention just on individual systems. The approach must be multidisciplinary. Knowledge of individual conditions typical for HD patients can help to improve the overall cure management and overall approach to the kidney patients. Because individual co-morbidities are interrelated, relevant issues will be discussed across following chapters.

\subsubsection{Impact of selected factors of physical fitness in HD patients}

It is important to keep in mind specific rules of physical activity performance among HD patients that are associated with identified limitations and to adjust the intensity and type of physical activity if necessary [36, 62-65].

The most limiting factors of aerobic capacity are: increased concentration of "uremic toxins" in blood, anemia, metabolic acidosis with developed muscle malfunction, uremic myopathy, uremic polyneuropathy, hypercalcemia, cardiovascular abnormality, or hypokinesis $[9,36$, 66 , 67]. Maximal exercise load at deconditioned HD individuals is only at $51 \%$ of population norms and the most limiting factor is muscle fatigue which is closely related to injury and breathlessness. Therefore exercise intensity close to anaerobic threshold, dynamic exercises with heavy weight, or exercises involving rapid intensity changes are not recommended for HD patients. On the other hand aerobic activities characterized by low secretion of lactose are beneficial. Interruption of exercise or immediate intensity decrease are recommended when breathlessness, muscle fatigue, or heart rate above training levels are experienced.

Factors negatively impacting aerobic fitness are: reduced cardiac function due to low trainability and decreased heart rate response to exercise load, low transport capacity of blood for oxygen due to developed anemia, diminished muscle function due to uremic myopathy and atrophy. The cause of diminished physical fitness among HD patients is impaired metabolic activity of skeletal striated muscle due to: depletion of adenosine triphosphate (ATP), depletion of energetic substance such as glycogen, limited oxygen exchange, acidosis, intracellular electrolyt disorders, and constant muscle tissue loss caused by catabolic processes. Oxygen distribution to exercising muscles is decreased due to a combination of low cardiac function (limited chronotropic reaction to physical loading) with low transport capacity of oxygen (anemia) and low utilization of energetic substances (enzymatic blockage and detraining). Physical fitness of HD patients is influenced by muscle weakness (reduced ability to utilize energetic substances), uremia, deconditioning, and decreased heart response (due to polyneuropathy) to physical activity [68]. 


\subsubsection{Anemia and physical fitness}

Common accompanying signs of physical activity are diminished blood transport capacity for oxygen, premature onset of muscle fatigue, lowered performance, diminished maximal oxygen consumption, etc. Anemia is accompanied by metabolic adaptation of the organism to a lower oxygen supply which negatively impacts the reaction to physical activity. Inadequate oxygen supply to mitochondria is the cause of insufficient anaerobic energy metabolism even at lower intensity levels. Therefore the increased metabolic acidosis and lungs' ventilation followed by breathlessness is further developed in HD patients. Patients' reaction is characterized by high heart minute volume influenced by high heart rate at almost normal levels of the end-systolic volume. The levels of anaerobic threshold, maximal oxygen consumption $\left(\mathrm{VO}_{2 \max }\right)$, maximal vessel oxygen as well as other relevant factors affecting physical fitness and efficiency are seriously decreased.

Ulmer et al. [69] points out decreased working capacity by $50 \%$ due to anemia, especially immediately after the dialysis procedure. Long-term changes of complete blood count among ill individuals are associated with oxidative metabolic changes. Therefore high intensity activities and explosive sports or exercises are inappropriate for HD patients with anemia. It is crucial to monitor side effects of physical activity such as fatigue, nausea, breathlessness, or head pain and to adjust intensity if necessary. Aerobic performance of HD patients can be improved by gradual endurance training.

\subsubsection{Hypertension and physical fitness}

As mentioned earlier most of the HD patients suffer from hypertension. According to published studies reviewed by Parsons et al. [61] 50-90\% of HD population has a level of blood pressure higher than $140 / 90 \mathrm{mmHg}$. Physical activity is always accompanied by increased heart rate and blood pressure which produce higher demand of heart to a supply of blood and oxygen. Such phenomenon is among hypertonic patients even increased therefore blood pressure reaches undesirable levels during physical activity as well as resting. Thus the antihypertensive pharmacotherapy is often required despite its negative impact on the reaction of cardiovascular apparatus on physical activity. It is absolutely crucial to know all drugs and customize the actual type and intensity of physical activity according to individual needs.

Several indicators such as heart rate (HR), blood pressure, (BP), subjective perception of physical activity and its intensity measured by Borg scale are regularly monitored during physical activity [70,71]. It is impossible to use a classical calculation of maximal heart rate and subsequently training heart rate (220 minus age multiplied by $60-70 \%$ ) due to present complications and medication [72]. Intensity of physical activity must be determined individually based on the results of prior objective and subjective testing and constantly controlled by the Borg scale [70, 71]. Static strength exercises are not recommended for patient with hypertension. Breath holdings combined with static and dynamic exercises of high intensity, sudden position changes, or exercising with hands above head is strictly forbidden. Heart rate of individuals using beta blocators is during physical activity significantly lower as compared to healthy population without the use of such medication. Any physical activity is 
strictly contraindicated for patients with rest arrhythmia, tachycardia, or bradycardia without obvious reasons.

However results of various studies conducted to evaluate the influence of physical activity on lowered blood pressure provide inconsistent conclusions. For example Hagberg et al. [30] found that blood pressure can be lowered from $155 \mathrm{mmHg}$ to $135 \mathrm{mmHg}$ after only 3months conditioning intervention. Deligiannis et al. [73] found similar but moderate decrease of blood pressure, from $145 / 87$ to $136 / 79 \mathrm{mmHg}$. Interestingly Ridley et al. [74] and Miller et al. [59] found significant decrease of antihypertensive pharmacotherapy consumption after just 3-months intervention although their research did not support the results of the two previous studies. Similar results were provided by Miller et al. [59]. In his research study on average $36 \%$ of patients reached decreased amounts of antihypertensive pharmacotherapy which lead to economic savings of 885 USD per patient per year. On the other hand research studies conducted by Parsons et al. [61], DePaul et al. [75] and Cappy et al. [76] did not support such positive findings. According to their results only 3-months intervention does not ensure significant decrease of blood pressure or the decrease of antihypertensive pharmacotherapy consumption. The question is whether the length, intensity, and type of physical activity as presented in the studies are sufficient or not.

\subsubsection{Atherosclerosis and physical activity}

Failures of lipid metabolism are often presented among ESRD patients. One of the main risk factors of atherosclerosis is insufficient physical activity which is very common for HD patients. Research studies [29, 68, 77] conducted to evaluate effect of 6-9 months training on lipid metabolism in HD patients provided evidence that exercise decreases levels of triacylglycerol (TGC) to $25-39 \%$ and increases plasmatic high-density lipoprotein (HDL) to $22-23 \%$ (hypertriglyceridemia and lowered level of HDL might be caused by decreased function of lipoprotein lipases) [78]. Nevertheless it is necessary to consider possible negative consequences of the high demand on circulation during the physical activity. Physical activity is associated with accelerated blood flow. In accordance with hydrodynamic law the speed of the flow - both laminar or turbulent - has specific pressure demands on the vessels' walls. Regardless the speed turbulation always occurs in the bending or branching of for example coronary vessels. Therefore the highest demand on the vessels' wall is presented right there. It is assumed that the increased speed during for example physical activity causes high demand on the vessels' wall at the identified areas. This is especially thru when atherosclerosis is presented. In such cases it is required to adjust physical activity appropriately. However physical activity is a very effective prevention to atherosclerosis.

\subsubsection{Diabetes mellitus and physical activity}

It is absolutely crucial to check the level of glykemia before a start of any physical activity. The risk of hypoglycemia or hyperglycemia is high among decompensated diabetes individuals during physical activity. Physical activity recommendations should be followed when indicating physical activity in HD patients [62-64, 79]. 


\subsubsection{Malnutrition and physical activity}

Malnutrition increases the risk of morbidity, mortality, and diminished quality of life among renal disease population [80]. Malnutrition, muscle tissue loss, and muscle fatigue are closely related to lower physical activity levels of HD patients [81-83]. Also malnutrition is associated with the retention of "uremic toxins" which further supports suppression of protein synthesis and stimulates its catabolism processes [16]. Symptoms such as loss of active muscle tissue, muscle atrophy, and muscle fatigue are closely related to protein metabolism malfunctions. It is important to consider that similar losses naturally occur with age. Therefore the effort to maintain muscle tissue and power for as long as possible is especially important for HD patients because the majority of them is over 60 years and the issues of independence and self supported life are very real $[84,85]$.

Several studies $[13,37,86-88]$ suggest that the muscle power (resistance) training represents the most effective way how to support lipid synthesis in muscles, reduce their catabolism, and support hypertrophy of muscle fibers. Kouidi et al. [13] and Sakkas et al. [88] conducted many studies about muscle fiber morphology (m. gastrocnemius, $\mathrm{m}$. quadriceps femoris) in HD patients during regular physical activity. They found that 6-months intervention courses may reduce an atrophied tissue from $21 \%$ to only $2 \%$. Also studies focused on issues of nutrition status in HD patients and the effect of physical activity provide clear evidence that regular physical activity is beneficial as soon as after 3-months of training [76, 89, 90].

\subsubsection{Hypokinesis and physical fitness}

Limited physical activity - hypokinesis - has negative impact on physical fitness in HD patients. One of the causes might be the fact that those patients spend 600-1000 (4-6 weeks) hours per year sitting or lying during dialysis procedure which is in most cases required 3 times per week for 4-5 hours [36]. It has been published that due to this fact 30 years old patients have working capacity only at $75 \%$, 30 to 60 years old at only $57 \%$ and over 60 years old at only $40 \%$ of healthy population norms.

In 1981 Gutman et al. [26] conducted study evaluating quantity of physical activity and independence in activities of daily living (ADL) in 2191 HD patients. It was found that only $60 \%$ of study participants were completely or partially independent of outside help. Another $20 \%$ were independent only at home environment and remaining $20 \%$ were completely dependent on the help of others. According to Kouidi et al. [40] HD patients are interested to participate in long-term organized physical activity programs and their adherence is in general high. The authors concluded that after 4 years of the study duration those HD patients who fully completed interdialysis physical activity program reached great results. $70 \%$ of them experienced increased oxygen consumption during the physical activity, 53\% of them could participate in longer physical exercises, and $52 \%$ of them improved their anaerobic thresholds. On the other hand those HD patients who dropped of the program experienced rapid loss of physical fitness and muscular strength after only 4 weeks. According to life-long experiences of Daul and Schäfers [49] the organized exercise sessions during dialysis are the only effective way for the majority of dialysed patients how to regularly participate in physical activity. 


\subsubsection{Hemodialysis procedures and physical fitness}

Lichtenbelt et al. [91] compared the values of working capacity, cardiac output, heart rate, vessels' volume, or arteriovenous oxygen extraction in intradialytic and interdialytic exercise programs and did not find the difference. Arterial volume of oxygen increased during maximal physical activity faster among patients in the intradialytic exercise program as compared to the patients in the interdialytic exercise program. Hemodialysis itself does not cause acute response on the exercise except for trivial influence on hemoconcentration. Barnea et al. [92] did not find any difference in working capacity immediately prior and 12 hours after the dialysis. One of the possible explanations of a speedy secretion of "uremic toxins" during hemodialysis seems to be the physical loading. There are several studies [61, $76,93,94]$ focused on the effect of physical loading during hemodialysis on levels of urea in serum and in dialyzer. The indicator of evaluation of hemodialysis success is the $\mathrm{Kt} / \mathrm{V}$ ratio ( $\mathrm{K}$ = clearance of urea in dialyzer in $\mathrm{ml} / \mathrm{min}$; $\mathrm{t}=$ time of dialysis in minutes; $\mathrm{V}=$ volume of total body fluids which is equal to $60 \%$ of patient's weight). Cappy et al. [76] and Kong et al. [93] provided evidence that the $\mathrm{Kt} / \mathrm{V}$ ratio can be increased by $13 \%$ after regular physical activity during hemodialysis. This increase is caused by higher blood flow through the working muscles. Parsons et al. [61] focused his research on the effect of 8-weeks physical activity program during hemodialysis on the more effective removal of uremic toxins. Also the effect of the program on working capacity and the subjective quality of life in HD patients was evaluated. It was found that the program slightly increased level of urea in dialyzer but the $\mathrm{Kt} / \mathrm{V}$ ratio remained the same.

Due to the motion of body fluids during the dialysis and associated changes in the blood pressure the most appropriate and optimal time for physical activity during hemodialysis is considered the second hour of the treatment. Physical activity is not recommended at the beginning of the treatment because of high extracellular volume and possible increase of blood pressure. On the other hand the end of the treatment (fourth hour) is known for increased risk of hypotension events and cramps [61, 62, 95].

\subsubsection{A-v shunt and physical fitness}

A-v shunt requires special care during physical activity. It is not recommended to wear watch or bracelets on the arm with the a-v shunt. A-v shunt should be protected from rubbing by sterile gaze also during swimming or other water activities. Any contact sports with the risk of falling or being hurt as well as sports for couples involving hands holding are not recommended. Also lifting of heavy objects should be avoided. On the other hand exercises with light objects such as overballs, light balls, and blow up balls are appropriate. Activation of the arm with a-s shut supports blood flow, improves vessels' elasticity and function of the $\mathrm{a}-\mathrm{v}$ shunt in general. Although it is not recommended to test heart rate in the area of $\mathrm{a}-\mathrm{v}$ shut it is possible to do so in the case of peripheral nervous system disorders. Otherwise hand palpation on the arm with a-v shut is not accurate because of false values of diastolic blood pressure. 


\subsubsection{Skin changes, bleeding and physical fitness}

Skin of most HD patients is frail and sensitive to injury. In addition healing is significantly worsened among diabetics. Increased bleeding is enhanced by antithrombotic treatment, thrombosis due to uremic changes, and vessel's wall frailty. It is recommended to avoid all activities that may lead to skin damages.

\subsubsection{Uremic myopathy, polyneuropathy and muscular activity}

Daul et al. [36] provided evidence that loss of muscular strength may be caused by a degenerative change in muscle cells which is known as uremic myopathy. Additional research [96] discovered a hypertrophy of anaerobic fiber type I. in HD patients. In the most recent studies that use p-magnetic resonance spectroscophy was found out that except for morphological also metabolism functional changes occur in the muscles of dialysed patients [97, 98]. The most affected are muscles of lower extremities where the decline can reach $50-70 \%$ and where the muscle fatigue is the most apparent [99, 100]. Lower extremities are also affected by uremic polyneuropathy and muscular atrophy. At the same time sensitivity and coordination disorders are also often detected [36]. Physical activity should be focused on systematic strengthening of low extremities muscles. Other consequences of uremic stages are in detail described in the following section Motor System Disorders.

\section{Motor system disorders}

Prevalence of musculoskeletal complications which is already common in the population increases with longer life expectancy of HD patients [14, 55, 101]. Together with other complications musculoskeletal issues are responsible for rapid deterioration of functional abilities necessary for independent living and consequently diminished quality of life.

So far many research studies focused on motor system disorders in dialyzed patients have been recently published not only abroad [55, 101-103] but also in the Czech Republic [1]. In the following text are individual motor system disorder presented according to the most recent research findings. Table 1 at the end of this chapter presents discussed motor system disorders (MSD).

Common symptoms of such disorders include pain, limited dynamics, diminished muscular strength, early onset of fatigue, diminished sensitivity as well as other symptoms. The causes of all symptoms are often interrelated. Most of the disorders are caused by structural changes due to uremic stages but other causes such as sedentary lifestyle and other restrictions associated with renal dialysis treatment have been recognized and described. With the regard to multifactorial etiology relevant disorders are organized into groups according to location of the individual disorder as follows: disorders affecting whole motor system, joints, bone tissue, muscle tissue, peripheral nervous tissue, and other remaining disorders. 


\subsection{Disorders affecting whole motor system}

Dialysed patients have extremely low physical fitness and endurance. A primal cause has not been discovered so far but important factors negatively influencing fitness have been recognized and include anemia, uremic myopathy, decreased utilization of oxygen by working muscles [3, 13, 104] and sedentary lifestyle so common for HD patients [105].

Fatigue is in general described as weakness, feeling of exhaustion, and lack of energy [106]. It is one of the most often occurred problems among dialysis patients [107]. Fatigue prevalence reaches $60-97 \%$ and may be even 3 time higher as compared to healthy population [108]. Physiological and psychological causes of this fatigue are hypoparathyreoidismus, uremia, anemia, depression, diminished quality of sleep, psychosocial stress, physical inactivity [106], muscle energetic metabolism disorders, diminished central activation, muscle contraction failures, and neuromuscular transmission - symptom of uremic polyneuropathy and myopathy (in detail described later) [108].

Specific type of fatigue often presented among dialysis patients is so called postdialysis fatigue [109]. Its development is caused by many factors which can influence its level and duration. It is possible to ease symptoms by increased frequency of dialyses procedures [110]. The most important factor seems to be a level of daily habitual activity - less activity means stronger fatigue [109]. Fatigue is the most frequent obstacle to physical activities [111]. It is a very complex problem which from the point of view of nephrology requires multidisciplinary approach. However this field still suffers from lack of research focused on pathogenesis and adequate treatment [106]. Pharmacotherapy includes prescription of erytroprotein and other similar drugs controlling anemia [112, 113]. Effective non-pharmacological approaches are represented by endurance training during hemodialysis [114], yoga [115], or acupressure [116].

Another often very disturbing disorder detected in dialysed patients is a back pain most often low-back pain or lumbar pain [58]. Illness of certain organs evocated by nociceptive stimulation has a characteristic pattern of reactions in the motor system - not only in the correspondent innervations segments but practically in the whole motor system $[117,118]$. Then we are talking about so called visceral pattern [117]. Such changes may become a factor that keeps the problems such as in most cases pain presented [117]. Except for typical pain that most of us know as renal colic it is typical also already mentioned low-back pain [118]. Subjective difficulties depend on the range and stage of the illness [119]. Approximately $36 \%$ of patients suffer from low-back pain which is often associated with stability failures, muscle weakness, arterial hypertension, bone disorders, and cerebrovascular disorders [58]. One of the most frequent disturbance symptoms in dialysed patients is pain [17-20]. Pain associated with locomotor system disturbances reduces the functional capacity even in healthy population. Pain in combination with polymorbidity leads to a fast overall deconditioning and total functional capacity reduction [55] and consequently diminished QoL.

However this area of expertise still lacks the knowledge gained in research studies, especially the treatment methods are still underdeveloped [58]. Within physiotherapy intervention 
the most appropriate techniques appears to be a soft techniques, mobilization in blocked segments as and other blockages and spasms, electrotherapy treatments (solux, diadynamic streams, TENS), and reduction of defective movement stereotypes. Available medication includes salicylates, non-steroid antirheumatics, and analgetics. Myorelaxats are considered only rarely in most serious cases and just for short period of time [117].

Dialysis-related amyloidosis is a special kind of amyloidosis which attacks individuals in a long-term dialysis [120]. Patophysiology based on dialysis-related amyloidosis is storing of special kind of lipids (amyloid) in bone tissues, synovial, tendons, and peripheral nerves. Over $50 \%$ of patients suffer from dialysis-related amyloidosis after 20 years of dialysis treatment [121]. Consequently complications are detected mostly at motor system and include: cystic nidus in bone tissue, carpal tunnel syndrome, hands' tenosynovitis, destructive spondyloarthropathy, monoarthritis, polyarthritis and also periarthritis, spinal canal stenosis, cervico-occipital psedotumors, pathology fractures and so on [121-125]. Therapeutic approaches consist of prevention of the development as well as further progression, symptomatic therapy (conservative treatment, orthopedic interventions and physiotherapy), use of biocompatibility of peritoneal dialysis fluids [101] and of course kidney transplantation [121, 126, 127].

\subsection{Joints disorders}

Dialysis-related arthropathy is a syndrome specific for long-term dialysed patients and is described as a result of dialyses amyloidosis (see above) - sedimentation of amyloid protein in joint tissue [128]. Symptoms are observed at some patients between $4^{\text {th }}$ and $5^{\text {th }}$ year of dialysis but most often the symptoms develops as late as after 15 years of dialysis $[125,129]$. From the clinical point of view the disease is manifested by pain and stiffness of large and small joints on both sides, movement limitations, pain and stiffness of hands and axis joints, and spine canal syndrome [122, 125, 128, 130]. Rare exacerbations of inflammation mostly in metacarpophalangeal joints may resemble acute inflammation arthritis which can result in trigger fingers or even spontaneous tendon ruptures [128, 129]. In addition this disease can attack at about $20 \%$ of patients spinal vertebrae which is known as destructive spondyloarthropathy [131], especially in sub-axial and lumbar area $[122,127,132,133]$. In case of spine canal syndrome and destructive spondyloarthropathy the symptoms are treated by chirurgical decompression which is rather conservative approach. Acute monoarthrithis may be treated by non-steroid antirheumatics, corticoids, or by joint replacements [122]. Crystal-induced arthropathy due to sedimentation of elementar phosphat crystals is also considered a significant cause of acute joint inflammation among renal disease patients [122].

\subsection{Bone tissue disorders}

Kidney plays an important role in regulation system of bone and mineral metabolism [134]. Renal disease patients suffer from four different types of bone disorders which are together called renal osteodystrophy $[135,136]$. Bone changes follow imbalance of basic elements 
such as phosphor, aluminum [126], fluor, and strontium [137]. Production of those elements relies on several factors such as calcium-phosphor homeostasis, type of renal disease, or frequency and quantity of potentially toxic drugs. Renal osteodystrophy often worsens according to a renal disease progression, during hemodialysis, and culminates, in case of transplantation, at early post-transplant stage [135]. Renal bone diseases start simultaneously with ESRD when glomerular filtration reaches $50 \%$ of the original level. At the same time about $50 \%$ of the patients have abnormal bone histology [138]. Increased levels of alkaline phosphatase combined with high overall level of parathyroid hormone signify onset of the disease [139]. Around 70\% of all dialysed patients suffer from some bone disease characterized by higher number of fractures [138] which can be even 3-4 times higher than in healthy population [140,141]. Spontaneous fractures of ribs, ankles, vertebrae, leg, wrist and hip are the most typical [140]. Those fractures can be also caused by dialysis-related amyloidosis [125] which slightly differs from renal osteodystrophy by the presence of healing process [124]. Shiota et al. [142] describes spontaneous tendons ruptures in long-term dialysis patients usually where the tendon is attached to the bone because it causes bone frailty at the precise spot [142]. Except for earlier mentioned bone disorders long-term HD patients face high risk of osteoporosis due to age, sedentary lifestyle, nutrition, post menopause among women, or due to prior transplantation, or steroid treatment [138]. Bone mineral density measured by T-score was found in $79 \%$ of patients in lumbar vertebrae and in $59 \%$ of patients in femoral neck [139]. Lower bone mineral density was found in older dialysis women [143]. Bone mineral density should be regularly tested among all patients after they reach 3 years of the dialysis treatment because it is a great early indicator of bone fractures [140]. Patients with one of the bone disease should be supplemented by bisphosphonates - drugs that influence bone structure and mineralization [135]. Physical activity involving jumps with higher risk of fall or contact sports with a danger of potential crash are not recommended. Among individuals suffering from end stage form of renal osteodystrophy any group exercise involving walking or running should be totally avoided. Instead physical activity such cycling, swimming, water exercise in general, sitting exercise, or cycling ergometer training is highly recommended. The goal of physical activity is to support production of the bone cells and strengthen the bone structure. At the end it is important to mention that weight-bearing exercise supports successful treatment [144].

\section{Peripheral nervous tissue disorders}

Uremic peripheral polyneuropathy is one of the most common neurological complications in CRF $[103,145,146]$. The most plausible causes are abnormalities in peripheral nerves such as axial degeneration accompanied by secondary demyelization [145, 147]. Prevalence of uremic polyneuropathy is according to the most recent studies high. It reaches $60-100 \%$ among all CRF patients [148] and 87\% among dialysed patients [149]. Neuropathy in general thrives at the glomerular filtration (GF) below $12 \mathrm{ml} /$ minute. This disease has a slow start and its development takes months. It is typically characterized by distal symmetric process more obvious on the lower extremities rather than the upper extremities [148]. This disease 
is accompanied by muscle weakness and atrophy, areflexia of deep tendons reflexes, changes or total loss of sensitivity, and gradual spreading of neurologic deficit [146, 150]. However the symptoms may be stabilized during the dialysis treatment [146]. It is recommended to maintain serum $\mathrm{K}(+)$ within the normal range between individual dialysis procedures [148]. Pharmacotherapy has many side effects and in hemodialysis patients it is not effective [105]. A total recovery can be observed after successful kidney transplantation [146] but only if degeneration did not reach the advanced stage and if most of the axons were not damaged [151]. Noteworthy more than $50 \%$ of the ESRD patients suffers from neurological complications caused by diabetic peripheral polyneuropathy. This problematic is in detail discussed elsewhere [152, 153].

Sensitivity of peripheral nerves is increased during uremia. That is why individuals with ESRD have higher risk of mononeuropathy. Nervus ulnaris and nervus medianus are the two nerves that are affected the most often [154].

All dialysed patients with hand paresthesia are recommended to electrophysiology examination [155]. Carpal tunnel syndrome is treated by a surgery [126, 155-158] which is also used for ulnar nerve blockages especially when the conservative treatment is not effective and when the motor deficit is still worsening [159]. Kidney transplantation is considered to be the best preventive approach $[126,156]$.

Within physical activity application the attention should be paid to diminished concentration ability, restrained reaction of the organism on physical load, rapid onset of fatigue, motor coordination and fine motor skills malfunctions, muscle atrophy, disposition of orthostatic collapse especially during position changes, and diminished perspiration. Fatigue increases the risk of falling during the exercise. A risk of high blood pressure is increased during the coordination overload. HD patients often suffer from overheating, increased hear rate and even tachycardia, or risk of hypotension and collapse due to diminished perspiration. Both subjective and objective sighs of fatigue should be constantly monitored during physical activity. Physical activity session should be immediately terminated in case of failure of coordination and concentration. It is recommended to gradually train gait (on flat surfaces, off road, with obstacles, and with sudden changes of direction) in case of the presence of peripheral polyneuropathy, sensation, and coordination failures in low extremities. Recommended is also a correction of muscle atrophy by systematic strength training. HD patients vulnerable to orthostatic collapse should avoid sudden position changes or long-term standing. Due to low perspiration it is not recommended to perform high intensity physical activity. In case of high outside temperatures the intensity should be decreased even more, important is also a proper clothing, skin color and heart rate monitoring.

\section{Muscle tissue disorders}

Functional and structural muscle abnormalities in ESRD patients due to uremic state are in general called uremic myopathy. Hypothetical patophysiological factors are anemia, mito- 
chondrial metabolism disorders and abnormal oxygen transport [160]. Morphological muscle changes of uremic patients consist of muscle atrophy, diminished endurance and fitness, and rapid onset of fatigue [98]. Usually are observable at levels below 25ml/min GF and progression advances together with decrease of renal function [160]. Overall prevalence estimation is $50 \%$ of dialysed patients [161]. Another factors influencing reduction of muscle tissue in uremic patients includes: sedentary lifestyle, hypertension, diabetes mellitus [160], uremic peripheral neuropathy $[13,147]$ as already described, and so called MIA syndrome (Malnutrition - inflamation - atherosclerosis) which can limit energy supply to muscles. Most studies are based on bioptic examination of muscle and clinical findings. Electromyography examination and muscle enzymes are usually within normal range. Specific treatment of uremic myopathy does not exist. Important is prevention by high-permeable dialysis membranes or by kidney transplantation [160]. Several studies found that some improvement can be achieved by aerobic training, prevention, treatment of secondary hyperparatyreoidism, dietary changes, renal anemia treatment by erythropoietin [160,162,163], or vitamin D supplementation [164]. Over $65 \%$ of dialysed patients complain about muscle problems due to mineral metabolism disorders [165]. It is necessary to distinguish between uremic myopathy and other malfunctions caused by water and electrolyt collapse [166]. Another disease affecting uremic muscle is a progressive parathyreoid myopathy which itself is a great indicator of parathyreoidectomy [167]. Muscle inflammation or so called fokal myositis can be detected during repetitive muscle pains of low extremities [168].

\section{Other disorders}

Restless leg syndrome is a disorder associated with uremia [154]. It is a senzomotor neurological illness characterized by constant leg motion, unpleasant feelings in lower extremities such as itching, burning, nipping, twitching, pain, and worsening of those feeling while resting (before falling asleep or at night) with occasional relief after activity performance. Etiology among dialyzed patients is unknown but it is assumed that relates to peripheral neuropathy, ESRD [154], and diminished physical activity [169]. Prevalence of the syndrome differs across studies form $10-30 \%$ [170], 58\% [171] or 60\% [172]. Higher prevalence is associated with diabetes mellitus, supplementation by $\mathrm{Ca}^{2+}$ antagonist, and dialysis treatment duration [171]. Individuals suffering from this syndrome are not able to rest, have low quality of sleep, suffer from insomnia and depression, and are under constant emotional stress [154, 173]. Patients on dialysis should focus for example on anemia reduction and supplementation by dopamine agonist. Attention should be paid to drugs' side effects [174]. Physical activity, especially aerobic and strengthening exercise 3 times per week can reduce symptoms by $39 \%$ [175]. All symptoms disappear only few weeks after successful transplantation [174].

Another neurological complication includes several types of uremic involuntary movements due to encephalopathy, medication, or structural lesion [154]. Some studies describe flapping tremor (asterixis), action myoclonus-renal failure syndrome [154], uremic twitch-convulsive syndrome [176], chorea [177], etc. 


\begin{tabular}{|c|c|c|}
\hline $\begin{array}{l}\text { Group of disorders according to } \\
\text { impacted tissue }\end{array}$ & Name of disorder & Subgroups \\
\hline \multirow[t]{4}{*}{ Whole motor system } & \multicolumn{2}{|l|}{ Low exercise capacity } \\
\hline & Fatigue & $\begin{array}{l}\text { Muscle fatigue } \\
\text { Post-dialysis fatigue }\end{array}$ \\
\hline & Reflex visceral pattern & $\begin{array}{l}\text { Pain - most common is Low Back pain } \\
\text { Muscle spasms, trigger points } \\
\text { Decreased Joint Flexibility } \\
\text { Joint blocks } \\
\text { Disorders of Stability } \\
\text { Defected Movement Stereotypes }\end{array}$ \\
\hline & Dialysis-related Amyloidosis & $\begin{array}{l}\text { Bone tissue } \\
\text { Synovial tissue } \\
\text { Ligament tissue } \\
\text { Peripheral nerve tissue }\end{array}$ \\
\hline \multirow[t]{3}{*}{ Joint tissue } & Dialysis-related Arthropathy & Shoulders, knees, etc. \\
\hline & \multicolumn{2}{|l|}{ Infectious Discitis } \\
\hline & \multicolumn{2}{|l|}{ Crystal-induced Arthropathy } \\
\hline \multirow[t]{2}{*}{ Bone tissue } & Renal osteodystrophy & $\begin{array}{l}\text { Spontaneous bone fractures } \\
\text { Spontaneous ligament ruptures }\end{array}$ \\
\hline & \multicolumn{2}{|l|}{ Osteoporosis } \\
\hline \multirow[t]{3}{*}{ Peripheral nerve tissue } & \multicolumn{2}{|c|}{ Uremic Peripheral Polyneuropathy } \\
\hline & \multicolumn{2}{|c|}{ Diabetic Peripheral Polyneuropathy } \\
\hline & Mononeuropathies & $\begin{array}{l}\text { n. ulnaris, n. medianus, some cranial } \\
\text { nerves }\end{array}$ \\
\hline \multirow[t]{4}{*}{ Skeletal muscle tissue } & \multicolumn{2}{|l|}{ Uremic myopathy } \\
\hline & \multicolumn{2}{|c|}{ Mineral metabolism malfunctions } \\
\hline & \multicolumn{2}{|c|}{ Progressive Parathyroid Myopathy } \\
\hline & \multicolumn{2}{|l|}{ Focal myositis } \\
\hline \multirow{2}{*}{$\begin{array}{l}\text { Others } \\
\text { (non-classifiable into groups) }\end{array}$} & \multicolumn{2}{|l|}{ Uremic restless legs syndrome } \\
\hline & $\begin{array}{l}\text { Uremic Involuntary } \\
\text { Movements }\end{array}$ & $\begin{array}{l}\text { Asterixis (flapping tremor) } \\
\text { Action myoclonus-renal failure } \\
\text { syndrome } \\
\text { Uremic twitch-convulsive } \\
\text { Chorea }\end{array}$ \\
\hline
\end{tabular}

Table 1. The Motor System Disorders (MSD) in Dialysis Patiens [18]. 


\section{Quality of life of HD patients}

Perception of ESRD individuals differs according to psychological, social, and medical point of view. Many different approaches how to deal with psychological and social issues and dialysis treatment have been developed and are further improved. All approaches are consistent in the opinion that dialysed patients carry a great burden and that the most important goal of all involved personnel is to ease this burden [2].

Dialysis patients as any other chronically ill individuals are exposed to a great deal of stress related to the life threatening situation. Significant component of the stress is a total dependence on medical devices, hospital and medical personnel which may be more stressful then the life threatening situation itself. The value of independent life is sometimes so strong that it is impossible to deal with the treatment which often results in depression, aggressive behavior, self destruction behavior, etc.. Dialysis procedure itself is very stressful because it involves fear from the connection to a dialyzer, pain and other related complications. Worry some are also potential failures of dialyzer, inability to predict process of dialysis, fear from the presence of other patients during complicated cases, etc.. The stress of dialysis patients is strictly specific due to various disease symptoms and demanding treatment. Other stresses typical for HD patient are as follows: loss of close persons, diet restrictions, free planning restrictions, increased time and space needs, dependence on the others, loss of physiological functions (urinations, sexual activity), increased aggression and constant threat of death.

Even dialysed patients are interested in quality of life, wisdom, and dignity. Important moment that improves patients' quality of life is their participation in social activities, social interaction, and other consequent pleasures. Social network represents important support system that helps to live satisfactory life despite the disease [178]. Without the support system patients usually experience more complications, are more often hospitalized, and as a result of worsened health status they eventually prematurely die [179].

In fact quality of life and physical activity are closely associated. Physical activity can be perceived as a basic tool for socialization because the group stimulation typical for physical activity participation is very effective. The most important is social interaction which is absolutely crucial for all humans. Unique experiences achieved during physical activity, game or sport are positive distractions from permanent pressure of a "serious" life. Many studies concluded that physical activity is unavoidable component of healthy lifestyle and very effective tool that can release negative symptoms of the stress. Protective effect of physical activity is based on various mechanisms on various levels of psychical and somatic regulation. Well known studies provide clear evidence that physical activity can improve quality and length of life. Physical activity programs are secondary components of complex treatment $[3,10,14,15,21,28,37,38,40,48,180]$.

Physical activity can significantly ease depressive and anxiety symptoms, strengthen selfconfidence, improve sleep, improve adaptation to stress, improve social interaction, support of social re-integration, etc.. Important part of regular group physical activity is participants' mutual understanding and social integration [181]. Despite all benefits it is relatively diffi- 
cult to change lifestyle habits and up to date daily routines even for healthy population. This is especially thru for dialysis patients due to among others fear of further worsening of the situation. Therefore intense motivation is required. But in general it is possible to conclude that physical activity significantly improves quality of life of dialysed patients and reduces mortality.

\subsection{Importance of physical activity for elderly dialysis patients}

CKD has recently been recognized as a number one chronic diseases primarily affecting the elderly [182]. Coresh et al. [183] found an increased prevalence of CKD among individuals over 70 years from $38 \%$ to $47 \%$ in the period from 1999 to 2004 . According to US Renal Data System from 2008 the median age of a new dialysis patient is now 65 years. The fastest growing group is over 75 years. In renal patients advancing age was found to be independently associated with higher scores on the physical dimensions of Sickness Impact Profile [184].

Crucial indicator of quality of life among older patients is the degree of their independence and maintenance of the ability to continue living at their homes for as long as possible. All measures that may reduce the risk of complications and at the same time increase or maintain independence are very much welcomed from the patient as well as from society point of view. According to Kutner and Jassal [185] it is a great clinical challenge to identify factors that can support functional status of elderly dialysis patients. It has been clearly documented that regular physical activity has positive effect on the overall functional and psychosocial status of RDT patients of all ages [36, 42, 56, 185, 186]. The consensual aim of most of earlier mentioned studies was to include the appropriate form and amount of physical activity for patients who express the will to improve their physical fitness. Sedentary and already dependent elderly patient on RDT represents a great burden and expenses for health care and medical personnel [187]. Kutner [188] and many others suggest that some form of regular physical activity in routine care is a key opportunity to enhance functioning and well-being of elderly renal patients. Regular physical activity could improve elderly renal patient's physical parameters such as strength, balance, mobility and therefore potentially lower the risk of falls [189]. Also dimensions of person's HRQOL can be significantly improved by regular physical activity. Cycle exercise during dialysis is safe even in older HD patients with multiple co-morbidities [190]. It results in walking ability improvements and lower extremities muscle strength gain. Exercise in later life is a great way of social interaction and also a way to meet new people and thus to reduce loneliness [187]. The major goals of rehabilitation and physical activity programs for older patients are as follows: maintenance and improvement of overall physical fitness with the regard to the actual level (it is not necessary to reach the pre-disease stage but rather to maintain or improve fitness within actual capacities); improvement of mental status and mood; identification of areas of functional fitness that are weakened and thus are subjects for the therapy; group low intensity activities - exercises focused on stability corrections, joint flexibility improvements - walking (on the flat surface, off road, with help, without help); stretching exercises; isometric strength exercises - during dialysis; individual exercise program with respect to the results 
of entry tests; pain monitoring; overall improvement of physical fitness of elderly patient reduction of the need of assistive home care.

\subsection{Importance of physical activity for kidney transplantation preparation}

Certain level of physical fitness is necessary for dialysed patient on the waiting list for transplantation not only to guarantee successful surgery but to ensure high quality of life after the transplantation. Overweight is one of the risk factors that may complicate kidney transplantation. BMI over 35 is considered a contraindication to a surgery. The kidney transplantation itself is associated with a development of specific side effects (cause by immunosuppression) that includes increased appetite, increased fat tissue storage, etc. which all together leads to further weight gain. Long-term inactivity prior the transplantation and during the dialysis treatment results in reduction of physical fitness. Significant improvement of working capacity and tolerance of physical activity appears at the first year after the transplantation but only when prescribed physical activity intervention is strictly followed [186, 191, 192]. To participate in the post-transplant intervention appears to be much easier for those who already participated in physical activity programs prior the transplantation.

\section{Used methods}

\subsection{Selection of tools that can be used for evaluation of physical fitness and quality of life in HD patients}

\subsubsection{Recommended examination before the initiation of regular physical activity of HD patients}

Application of appropriate tests and proper examinations are necessary in order to avoid possible risks that are associated with physical activity of ESRD patients on dialysis treatment. Type, amount, and intensity should be individually indicated with the respect to the results of prior evaluation. The suggested physical activity should be also consulted with the physician in charge who should be able to provide additional information regarding patient 's health status. Important is basic anamnesis (ESRD courses, co-morbidities, pharmacotherapy), specific dialysis anamnesis (frequency and duration of dialysis session, duration of dialysis treatment, acceptance of dialysis treatment).

It is important to test actual potassium concentration before any physical activity recommendation. Too high or too low concentration may have fatal influence on heart rhythm because physical activity itself is associated with a lactate production in working muscles and a secretion of potassium ions which together significantly increases the potassium concentration. This is the reason why it is so important to know actual potassium level prior any activity. In addition the potassium level is also stimulated by beta blocators. Hypokalemic patients are threatened only rarely. The concentration of potassium in blood rapidly decreases after physical activity but because of the prior increase caused by physical activity there is a risk of developing tachycardia. Border values where physical activity is not recom- 
mended are: in hypokalemia $<3.5$, in hyperkalemia $>6 \mathrm{mmol} / \mathrm{l}$. High intensities or sudden ends of exercise without gradual calming are not recommended at all for those patients.

Actual status important for individual intensity indication should be examined by available motor and fitness test (for more details see below). Kinesiology assessment which includes examination of joint flexibility, muscle strength, muscle shortages, coordination, motor stereotypes, sensation, etc. can be used [193]. Prior physical activity experience and actual fitness level (before and after enrolment into dialysis group) are also important factors that should be considered for physical activity recommendations. In this case simple inquiry and interview are methods commonly used to collect needed information.

Important is also an assessment of body composition and nutrition status of the patients. Various methods such as isotope dilution, hydro densitometry, potassium level examination, neutron activation analysis, or BMI can be used. Another appropriate non-invasive method to evaluate body composition is a multifrequent bioimpedance analysis (BIA). Questionnaires evaluating quality of life such as KDQOL-SF36, SQUALA, WHOQOL, etc. are also appropriate for assessment of psycho-social status.

\subsubsection{Indication of physical activity}

Regular physical activity is especially beneficial for HD patients with motor and cardiovascular limitations. Indication includes: diminished physical fitness, joint flexibility disorders, weakened muscle strength, coordination disorders, renal anemia, renal osteopathy, arterial hypertension, carbohydrate metabolisms disorders and diabetes mellitus, lipid metabolism disorders [36]. Other details such as indications to the test termination or contraindication to the test execution are presented e.g. in publications of Daul et al. and ACSM [36, 63].

\subsubsection{Contra-indication of physical activity [36, 62, 63, 194]}

Total contraindications include malignant arterial hypertension $(240 / 120 \mathrm{mmHg})$, resting decompensated hypertension $(200 / 100 \mathrm{mmHg})$, unstable angina pectoris, heart failures, serious heart rate disorders without medication therapy, acute lung emboli, arterial events, advanced aortic stenosis, serious lung hypertension, acute illness (acute myocardial infarction, inflammations such as myocarditis, thrombophlebitis, fever, thyrotoxicosis). Partial contraindications include hyperkalemia $>6 \mathrm{mmol} / \mathrm{l}$, hypokalemia $<3,5 \mathrm{mmol} / \mathrm{l}$, serious renal osteopathy, serious uremic polyneuropathy, unstable angina pectoris, less serious heart rate disorders, some of the inborn or acquired valve malfunction, post myocardial infarction states, decompensated diabetes mellitus, patients reluctance to cooperation).

\subsubsection{Possibilities of physical fitness testing in HD patient}

There are several available tests of physical fitness appropriate for HD patients. The actual selection of the most suitable one depends on many factors such as motor ability and skills, actual health status, technical equipment, available space, and personnel experiences of the laboratory. The following list contains only the tests that are currently used and that proved 
to be suitable for HD patients (Senior Fitness Test Manual, 6-minute walking test, BalkeNaughton treadmill test).

\subsection{Senior fitness test manual [195]}

Senior Fitness Test (SFT) was developed to evaluate components of physical fitness that are necessary for everyday activities performance among individual over 60 (to 90 years) years which is perfectly appropriate also for younger but chronically ill or physically impaired patients. The test battery evaluates muscle strength, aerobic endurance, flexibility, and dynamic stability. The individual tests are safe to perform, fun to execute, and the battery has a sufficient validity $(0,8)$ and reliability. Importantly the testing does not require demanding technical equipment and large space and it is usable in the field settings. The SFT includes following tests: Sit to stand, Arm-curl, 2-minute Step test, Sit and Reach, Back Scratch, Up and Go, 6 minute walk test. According to the authors the battery evaluates "functional fitness" that has been defined as a minimal level of physical fitness that is necessary for independent performance of everyday activities safely and without undue fatigue. Results can be compared with the population norms presented at the SFT manual.

\subsection{6-Minute walk test}

Although this is one of the test from the SFT battery it is commonly used separately in a clinical practice as well as in research studies conducted by Orcy et al. [46], Golebiowski et al. [190], Ragnarsdóttir et al., Bulckaen et al. and Reboredo et al. [196-198]. The result of the test is a number of meters that a tested person can walk with maximal effort in precisely 6 minutes. The test should be performed in a tunnel or outside where it is not required to turn during the whole test. During testing instructor walks 3-4 meters behind the tested person and measures the distance. Rest heart rate (HR), breath frequency (BF) and blood pressure (BP) are examined before the test execution. The degree of effort is evaluated immediately after the test completion by Borg scale [70, 71] and by earlier mentioned indicators (HF, BF, $\mathrm{BP})$. Those are examined once again approximately 3 minutes later.

\subsection{Balke-Naughton treadmill protocol}

Another appropriate test for HD patients is Balke-Naughton treadmill protocol which is a submaximal intensity test executed on a treadmill [65]. Submaximal intensity is again determined by patient's subjective evaluation or objectively by heart rate. It is a gradual test with incline of $1,5^{\circ}$. Starting speed is set up at 2, 2.5 or $3 \mathrm{~km}$ per hour and is increased by $1-2 \mathrm{~km}$ per hour. Duration of each stage is 5 minutes with 1 minute of a rest break between the stages. Blood pressure is taken during each break approximately 20 seconds after the end of the stage. Spiroergometric indicators such as $\mathrm{VO}_{2 \max }$ are taken during walking. Also Borg scale is used after the completion of each stage [70,71]. Classical rest indicators such HF, BF, $\mathrm{BP}$, and subjective perception of intensity are assessed prior the testing. In addition it is recommended to monitor both rest and post-activity electrocardiograph for at least 5 minutes. Also heart response to each stage should be administered. 


\subsection{Bicycle treadmill test}

Bicycle treadmill test according to $\mathrm{WHO}$ protocol is another test requiring submaximal intensity $[8,36,61]$. Submaximal intensity is again determined by patient's subjective evaluation or objectively by heart rate. Starting power output is set up at $25 \mathrm{~W}$ and is increased by 25W each 2 minutes until maximal fatigue. HF, BF, BP are monitored 30 seconds before the end of each stage. Patient evaluates subjective intensity by Borg scale [70, 71] after each stage. $\mathrm{HF}, \mathrm{BF}, \mathrm{BP}$ is assessed prior the testing. Also it is recommended to administer rest electrocardiograph and to monitor heard response during each stage. Post-testing electrocardiograph, HF, BF, BP as well as subjective perception of intensity should be assessed after the test completion. The most common cause of the test termination among HD patients are pain and muscle weakness of lower extremities [36] followed by cardiovascular complications characterized by a significant increase of blood pressure.

\subsection{Subjective evaluation of exercise intensity}

Subjective intensity evaluation by Borg scale [70, 71] is applied when objective methods such as for example lactate concentration, spiroergometric indicators such as $\mathrm{VO}_{2}, \mathrm{VO}_{2 \max }$ or HR and BP are not accurate due to medical therapy (beta blocators). Borg RPE (,Rating of Perceived Exertion") scale was developed to evaluate subjective perception of intensity. The combination of both subjective and objective evaluations during physical testing provides unique information about patients' response to a physical testing and the tolerance to physical stress. RPE scale is a standardized tool to assess effort of tested person regardless age, gender, and origin. Basic presumption of clinical application is that perceptual and physiological responses are linear during various types and intensities of physical activity. This presumption can be used especially in testing of cardiac or HD patients with frequent cardiovascular complications that prevent them from maximal or submaximal effort exercises or tests. Results of Borg scale are valuable especially when the patient is treated by beta blocators because such group of drugs increases maximal oxygen consumption which in turn increases intensity of physical activity. RPE values between 12 and 13 corresponds with $60-$ $70 \% \mathrm{VO}_{2 \max }$ and 16 corresponds with $85 \% \mathrm{VO}_{2 \max }[62,199]$.

\subsection{Possibilities of evaluating quality of life in HD patients}

Quality of life can be evaluated by both subjective and objective approaches. However patient's subjective evaluation of own perception of the given situation, ability to actively participate in work, family and social life, and the overall satisfaction is absolutely crucial for evaluating and understanding of the quality of life [179]. The best tool currently available is the scoring system known as Health Related Quality of Life (HRQOL) [200]. The HRQOL score is one of the crucial factor influencing strategic decisions about the treatment and overall approach to the patient as well as nosologic unit [200]. HRQOL consists of standardized questions and answers which enable to effectively evaluate patient's health status. There are three types of questionnaires to assess quality of life - HRQOL [200] - Global assessment. This type provides general quality of life evaluation without a possibility to identify dysfunctions in individual areas or domains (physical, emotional, vitality, etc.). Generic 
type enables to identify details and actual differences between individual population groups which permit to compare individual specifics or similarities in the area of quality of life. On the other hand specific type is explicit for certain disease. It was developed to analyze the disease progress in time. Although the types are separated they often overlap. All the three types are in general accepted. Example is questionnaire SF- 36 (Short-form 36 Health Subject Questionnaire) which can be both global and generic. Other examples of generic assessments include: Karnofsky Performance Status Scale, Activities of Daily Living (ADL), Sickness Impact Profil (SIP), Time Trade-Off (TTO), SF 36. SIP identifies impact of the disease on health profile of patients. TTO enables to evaluate impact of the disease on working ability and independence [200]. Specific questionnaires were developed for individual diseases. Kidney Disease Questionnaire - KDQ is the most often one used in dialysed patients [179]. Features of both generic and specific questionnaire are presented in Kidney Disease Quality of Life Instrument (KDQOL) which also includes SF - 36. WHOQOL-BREF [201] and KDQOL-SF36 can be also used for evaluation of selected parameters HRQOL [202, 203]. So called European standard of Results for 8 components (domains) of HRQOL can be used for evaluation of SF-36 questionnaire results [204, 205].

\section{Physical activity programs suitable for HD patient}

Kutner and Jassal [185] created an entry and follow up criteria for integration into integrated care programs consisting of dialysis, and active short-term and long-term rehabilitation. The entry criteria include: active participation of motivated patient in rehabilitation program (active and voluntary cooperation), future potential of actual functional status improvement, activity of daily living (ADL), social interaction, and cognitive status. The follow up criteria include: cooperation of medical personnel on treatment adjustment, cooperation of dialyses nurses, multidisciplinary approach, long-term health status showing signs of improvements - positive reaction to impulses.

\subsection{Priority goals of physical activity programs}

Priority goal of physical activity program for dialysed patients is maintenance or improvement of physical fitness in order to support overall independence on other persons' help, social reintegration, work re-integration of individuals in productive age, and chances to live a life of healthy individuals. Both individual and group physical activity programs must respect uniqueness of each participant, prior physical activity experiences, actual physical fitness status, recommendation of physician in charge, and must not threaten ones health. Physical activity programs should include activities leading to maintenance or improvement of joint flexibility and muscular strength, compensation of muscle disbalances, renovation of dynamic stereotypes necessary for independent living, correction of muscle coordination disorders, and improvement of cardio-respiratory fitness. Additional benefits of physical activity include improvement of mental tolerance (self-confidence, self-evaluation, solving stressful situations), improvement of overall independency, better dealing with the disease and the treatment (shortened hospitalization, decreased morbidity and mortality), more enjoyable work and lei- 
sure activities, and enhanced dealing with the change of social roles in the family, work and society in general $[8,36,49]$. To satisfy all mentioned goals of physical activity programs is especially important for older patients, the majority of dialysed population.

\subsection{Types of physical activity programs}

Physical activity programs can be divided into group and individual exercises and, according to the timing within the complex HD treatment, into intradialytic and interdialytic physical activities. Each activity program is unique due to different acceptance of the complex treatment and the disease itself. German expert in nephrology divided physical activity programs into several groups according to the specific focus on individual components of physical fitness [36]:

Conditioning training: the goal is to maintain or improve overall fitness with the special attention to a development of basic motor abilities. Training includes exercises to improve joint flexibility, muscle strength and endurance, motor coordination and general physical condition.

Conditioning-endurance training: the goal is to improve cardio-respiratory fitness and to ease complication associated with ESRD and HD treatment (lower BP, carbohydrates and lipid metabolism optimization, etc.). Specific activities include all cyclic exercises (walking, jogging, cycling, etc.). HD patients should strictly follow individual intensity recommendation.

Strength training: the goal is to improve overall muscle strength, increase muscle volume, reduce atrophy of muscle fibers, support mineralization of the bone tissue, correct muscle disbalances, etc. Specific activities include resistance exercises and exercises with equipment such as weights, thera-bands, heavy bags with sand, etc..

Balance-coordination training: the goal is to correct coordination disorders and balance disorders which are associated with peripheral and central nervous system diseases. Specific activities include both individual and game based group exercises, exercises with balance equipment (overball, physioball, soft pad, etc.) and with gymnastic apparatus (bench, balls, ribstall)

Breath training: breath exercises are important for training of correct breathing stereotype which can be severely impaired among chronically ill individuals. The goal is to learn all types of breathing, coordinate breathing movements, harmonize function of organs, release overall tension, and optimize mental functions (stress, anxiety, and fear reduction).

Relaxation training: relaxation exercises are important part of physical activity programs of HD patients. Those exercises should be performed at the end of training session or individually. The goal of relaxation is to calm down all body processes, to release muscle tension in overloaded muscle groups, harmonize psychical functions, reduce risk of stress situations, re-gain strength and energy. Several relaxation techniques such as Schultz autogenic training, Jacobson progressive relaxation, or music are commonly used. Another example is Feldenkreis method which is based on body perception. 
Following physical activity variations may be included in individual physical activity program:

Bed exercises during hemodialysis: the exercise is focused on a development or maintenance of joint flexibility and muscular strength on the one free upper extremity (without a-v shunt) and both lower extremities, breathing exercises, training of cardiovascular fitness using bed side ergometer.

Exercises after dialysis (inpatient or outpatient): includes the same exercises as during hemodialysis with employment of all positions except for back laying and sitting position and the arm with a-v shunt. The exercise is focused on: relaxation and stretching of overloaded muscle groups, training of movement coordination and movement stereotypes, breathing and relaxation exercises.

Off-hemodialysis exercises (outpatient): includes of cyclic aerobic physical activity focused on overall physical fitness improvement. Final selection is made individually in accordance with patient's actual status and desires.

Following group exercises may be included within group physical activity program: water exercises, swimming, and outdoor activities such as walking, Nordic walking, games (petanque), relaxation, etc.

Physical activities and sports [72] such as badminton, walking on stairs, running, canoeing, rowing, fencing, skiing, table tennis, softball, volleyball, basketball, dancing, skating, tennis, squash, etc. are recommended for overall physical fitness improvement.

\subsection{Individual phases of physical activity programs}

Fundamentals of long-term physical activity among HD patients are the adaptation of motor and cardio-respiratory system to physical activity and training. The physical activity program is usually divided into several phases because of the presence of cardio-vascular complications. This is the same for other chronic conditions such as ischemic heart disease or acute myocardial infarction [36]. Individual phases differ by overall duration as well as duration of individual parts within the program (for details see Table 2.). However individual phases are interrelated and may be mixed. Also important role plays personality of each patient. Precise duration of individual phases is not presented because it is not described in the available literature $[8,36,62,63]$.

\subsection{Timing of physical activity programs within complex hemodialysis treatment}

Participation in physical activity in HD patients is also recommended between dialyisis when the organism tolerates the physical load the best. According to the available literature the most effective is one day after the dialysis treatment or immediately after the dialysis $[36,62]$. During those periods patients' water and electrolyte metabolism are stabilized. However earlier mentioned recommendations are individual because few individuals may suffer from high ultrafiltration leading to a pressure decompensation. On the other hand inappropriate physical activity timing is between the two hemodialysis, especially the second 
or the fourth day after the treatment (among patients with $1-2$ hemodialysis per week), or at the same day of the procedure or immediately before the procedure (among patients with 3 or more hemodialysis per week). Those periods are typical for accumulation of body fluids in the organism and decompensation of water and electrolyte metabolism. Interestingly physical activity seems to be beneficial and well tolerated during the hemodialysis procedure. Physical loading during the dialysis is often the only chance to participate in regular physical activity for most patients because they lack any extra time needed for preparation for the physical activity session including commute time [49]. The best timing for physical loading is during the second hour of the dialysis due to body liquids movement and changes in blood pressure. On the contrary the beginning and the end of the dialysis are inappropriate because of high extracellular volume and often increased blood pressure. This risk of hypotension events and cramps is too high $[61,62,95]$. The first responses of cardiovascular system to exercise become obvious after one or two months of regular intervention. But substantial improvement in physical fitness among HD patient occurs after six months or even one year of regular participation in physical activity program. Any termination of physical activity causes rapid decrease of physical fitness which is noticeable in few weeks and speeds up the progression of the disease $[8,40]$. This is the main reason why it is so important to stay physically active for as long as possible.

\begin{tabular}{|c|c|c|c|c|c|}
\hline Phase & Program duration & Focus & Type of physical activity & Intensity & $\begin{array}{l}\text { Exercise } \\
\text { session } \\
\text { duration }\end{array}$ \\
\hline 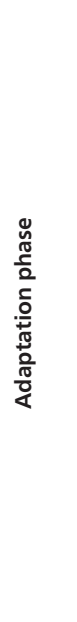 & 2-3 weeks & $\begin{array}{l}\text { Explanation of } \\
\text { advantages and risks of } \\
\text { PA; } \\
\text { Motivation to } \\
\text { participate in either } \\
\text { group or individual PA } \\
\text { programs. }\end{array}$ & $\begin{array}{l}\text { Simple exercises developed to } \\
\text { improve joint flexibility and muscle } \\
\text { strength, and to correct muscle } \\
\text { shortages; } \\
\text { Training of breath and exercise } \\
\text { coordination; } \\
\text { Training of own body perception and } \\
\text { body responses to exercise; } \\
\text { Conditioning exercise enriched by } \\
\text { breath gymnastics; } \\
\text { Beginning of easy cardio-respiratory } \\
\text { training using passive forms of bicycle } \\
\text { egrometer (bed-side ergometer or } \\
\text { bicycle ergometer with added } \\
\text { electromotor. }\end{array}$ & $\begin{array}{l}\text { Borg RPE scale } \\
7-9, \\
30-50 \% \text { of } \\
\mathrm{VO}_{2 \max } \text {. }\end{array}$ & $\begin{array}{l}15-30 \\
\text { minutes }\end{array}$ \\
\hline
\end{tabular}




\begin{tabular}{|c|c|c|c|c|c|}
\hline 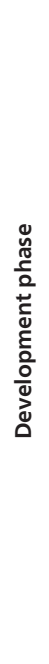 & $\begin{array}{l}\text { Several months } \\
(10-12 \text { weeks })\end{array}$ & $\begin{array}{l}\text { Follows the adaptive } \\
\text { phase and further } \\
\text { develops practiced } \\
\text { exercises; } \\
\text { Emphasizes muscle } \\
\text { strength (resistance } \\
\text { training using own } \\
\text { body weight) and } \\
\text { muscle endurance; } \\
\text { Stretching exercises; } \\
\text { Training of movement } \\
\text { coordination and } \\
\text { cardio-respiratory } \\
\text { fitness; } \\
\text { Breath and relaxation } \\
\text { exercises performance; }\end{array}$ & $\begin{array}{l}\text { Simple arm movements; } \\
\text { Vascular and respiratory gymnastics; } \\
\text { Exercises maintaining or renewing } \\
\text { muscle balance; } \\
\text { Joint flexibility and muscle strength; } \\
\text { Exercise and breathing coordination - } \\
\text { increasing number of repetitions; } \\
\text { Active interval cardio-respiratory } \\
\text { training using bed-side ergometer, } \\
\text { bicycle ergometer; walking and } \\
\text { jogging (off-dialysis); } \\
\text { Relaxation and breath exercise. }\end{array}$ & $\begin{array}{l}\text { Gradual } \\
\text { intensity } \\
\text { increase by } \\
\text { prolonged } \\
\text { duration of the } \\
\text { session or } \\
\text { higher number } \\
\text { of repetitions; } \\
\text { Borg RPE scale } \\
10-12 \\
50-60 \% \text { of } \\
\mathrm{VO}_{2 \max }\end{array}$ & $\begin{array}{l}40-60 \\
\text { minutes }\end{array}$ \\
\hline 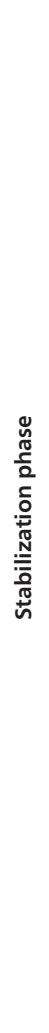 & $\begin{array}{l}\text { Follows the } \\
\text { previous phases } \\
\text { and continues for } \\
\text { as long as possible }\end{array}$ & $\begin{array}{l}\text { Motivation to regular } \\
\text { PA participation; } \\
\text { Group exercises } \\
\text { integration; } \\
\text { Both ambulatory and } \\
\text { home off-dialysis PA }\end{array}$ & $\begin{array}{l}\text { Games and group sports; } \\
\text { Conditioning, coordination and } \\
\text { strengthening exercises used as } \\
\text { follows: } \\
\text { a) adaptation phase - exercises to } \\
\text { maintain or re-new muscle balance, } \\
\text { joint flexibility, muscle strength (using } \\
\text { equipment and apparatuses), exercise } \\
\text { and breathing coordination - } \\
\text { duration of the phase is } 20 \text { minutes; } \\
\text { b) development phase-active } \\
\text { training of cardio-respiratory fitness } \\
\text { using bed-side ergometer, bicycle } \\
\text { ergometer, walking and jogging (off- } \\
\text { dialysis) }\end{array}$ & $\begin{array}{l}\text { Gradual } \\
\text { intensity } \\
\text { increase by } \\
\text { prolonged } \\
\text { duration of the } \\
\text { session, } \\
\text { incorporation of } \\
\text { new exercises } \\
\text { and more } \\
\text { challenging } \\
\text { versions of used } \\
\text { exercises, } \\
\text { strength } \\
\text { exercises using } \\
\text { various } \\
\text { equipment and } \\
\text { apparatus; } \\
\text { Interval forms of } \\
\text { cardio-vascular } \\
\text { training are } \\
\text { substituted by } \\
\text { endurance } \\
\text { forms with } \\
\text { gradual } \\
\text { increase of }\end{array}$ & $\begin{array}{l}60-90 \\
\text { minutes }\end{array}$ \\
\hline
\end{tabular}




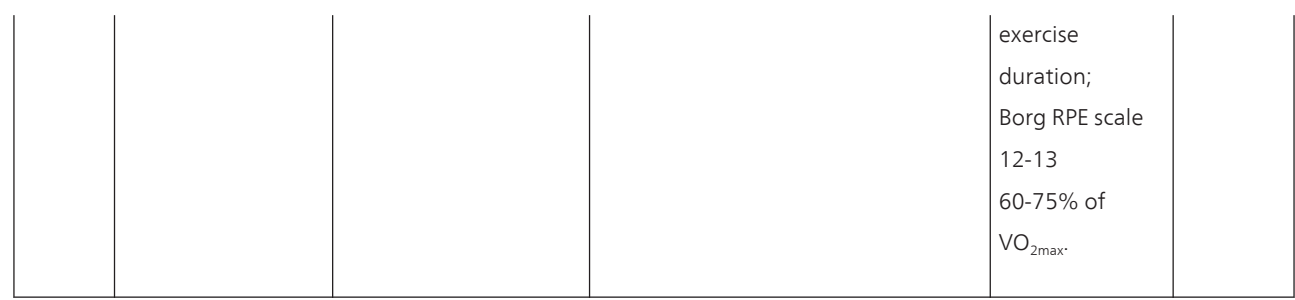

* PA: physical activity

Table 2. Individual phases of physical activity program for HD patients - intradialytic and interdialytic exercise

\subsection{Organization of physical activity session for HD patient}

Each session (group or individual) consists of three basic phases [33, 48, 52, 199]: a) warming-up b) main part - adaptation and development; c) Final part (cool down) - for details see Table 3. Duration and intensity of each session is set up individually based on actual condition of participants or group of participants.

\subsection{Indication for termination or intensity cutback during physical activity session $[8,63]$}

Indications for lowering intensity include dizziness, faintness, sudden increase of breathing frequency, shallow breathing, increase of HR above training values, articulation and speech failures, nausea, chest pain or pressure, joint and muscle pain, skin color change (sudden redness), paleness in the lips and nose areas, cold perspiration $[8,63]$.

Indications for termination are described at ACSM's Guidelines for Exercise Testing and Prescription [63].

\section{Research course}

\subsection{The focus of our research and used methods}

Lately (2007-2012), our research has been focused on the evaluation of the effects of regular physical activity on functional status and quality of life during hemodialysis. Since 2010 we have also paid our attention to identification of possible ways to improve functional status and quality of life in patients at the early stages after kidney transplantation. This chapter provides information about research studies that were conducted within two grant projects titled "Quality of the life in renal dialysed individuals of the Czech Republic and the possibilities of their affection through an exercise intervention" 2007-2009 Registration number 406/07/P443 and „Muscle metabolism after kidney transplantation: early exercise intervention, selective nutrition and gene polymorphism" 2009-2011 IGA MZ CR 173 (NS-10518-3/2009).

The major goal of our research studies was to introduce and apply intradialysis physical activity program and to evaluate its effect on physical and mental status and quality of life in 


\begin{tabular}{|c|c|c|c|c|}
\hline \multicolumn{5}{|c|}{ Organization of physical activity session } \\
\hline \multirow[t]{2}{*}{ Session part } & \multirow[t]{2}{*}{ Warming-up } & \multicolumn{2}{|c|}{ Main Part } & \multirow[t]{2}{*}{ Final Part } \\
\hline & & Adaptation part & Development part & \\
\hline Focus & $\begin{array}{l}\text { Body warm-up; } \\
\text { Injury prevention; } \\
\text { Stimulation of cardio- } \\
\text { respiratory function; } \\
\text { Coordination of CNS } \\
\text { processes; } \\
\text { Body preparation to } \\
\text { muscle work out. }\end{array}$ & $\begin{array}{l}\text { Development of joint } \\
\text { flexibility, muscle strength, } \\
\text { overall stretching and } \\
\text { relaxation of muscle groups } \\
\text { with tendency to shortages; } \\
\text { Training of coordination; } \\
\text { Coordination of exercise and } \\
\text { breathing; } \\
\text { Respiratory and vascular } \\
\text { gymnastics. }\end{array}$ & $\begin{array}{l}\text { Aerobic endurance } \\
\text { training. } \\
\end{array}$ & $\begin{array}{l}\text { Overall cool down of } \\
\text { the body; } \\
\text { Muscle relaxation and } \\
\text { stretching of loaded } \\
\text { muscles groups; } \\
\text { Harmonization of } \\
\text { overall physical and } \\
\text { mental status. }\end{array}$ \\
\hline Types of PA & $\begin{array}{l}\text { Simple complex exercises } \\
\text { improving joint flexibility; } \\
\text { Various types of walking; } \\
\text { Simple stretching exercises; } \\
\text { Games; } \\
\text { Bicycle ergometer and so } \\
\text { called bed side bicycle } \\
\text { ergometer. }\end{array}$ & \multicolumn{2}{|c|}{$\begin{array}{l}\text { Complex exercises improving joint flexibility; } \\
\text { Muscle strength and endurance improvement } \\
\text { (resistance training; training using own body } \\
\text { weight; dumbbells, theraband, gym equipment, } \\
\text { etc.) } \\
\text { Bicycle ergometer („,bed-side” ergometer); } \\
\text { Various types of walking, Nordic walking, low } \\
\text { aerobic activities, running, swimming, etc.; } \\
\text { Special games that attractively develops complex } \\
\text { abilities and motivate HD patients. }\end{array}$} & $\begin{array}{l}\text { Exercise without } \\
\text { loading; } \\
\text { Stretching exercises; } \\
\text { Breathing and } \\
\text { relaxations methods } \\
\text { (Feldenkreis, Jacobson, } \\
\text { Schultz); } \\
\text { Use of music (or } \\
\text { talking); } \\
\text { Yoga, power yoga, } \\
\text { Pilates. }\end{array}$ \\
\hline Intensity & $\begin{array}{l}\text { Bellow recommended } \\
\text { training HR values } \\
\text { Borg RPE scale 7-9. }\end{array}$ & \multicolumn{2}{|c|}{$\begin{array}{l}\text { At recommended training HR values } \\
50-75 \% \text { of } \mathrm{VO}_{2 \text { max }} ; \text { Borg RPE scale } 10-13\end{array}$} & $\begin{array}{l}\text { Bellow recommended } \\
\text { training HR values } \\
\text { Borg RPE scale 8-9 }\end{array}$ \\
\hline Duration & $\begin{array}{l}5 \text { - } 10 \text { minutes (in } \\
\text { accordance with individual } \\
\text { physical fitness and actual } \\
\text { PA program phase). }\end{array}$ & \multicolumn{2}{|c|}{$\begin{array}{l}20 \text { - } 60 \text { minutes (in accordance with individual } \\
\text { physical fitness and actual PA program phase). }\end{array}$} & $\begin{array}{l}\text { 5-10 minutes (in } \\
\text { accordance with } \\
\text { individual physical } \\
\text { fitness and actual PA } \\
\text { program phase). }\end{array}$ \\
\hline
\end{tabular}

* PA (physical activity)

Table 3. Characteristics of individual phases of physical activity session during hemodialysis

HD patients. Specific aims were to assess actual functional fitness and quality of life of the Czech HD patients, to evaluate prevalence of motor system disorders among HD patients, and to compare the results with healthy population. One of the studies was focused on eld- 
erly patients. Another study compared group of HD patients with patients after kidney transplantation. Results were published in both Czech and international journals and presented at international conferences/congresses [19, 207-214].

The criteria for inclusion in the studies were:

1. Previous medical examination and recommendation

2. Age over 18 years

3. Previous HD treatment for at least 4 months

4. Physical and mental ability to complete fitness tests and fill out HRQOL questionnaires

5. Positive attitude to physical activity

6. To be able to participate in exercise program at least twice a week

7. Expected inclusion in HD treatment program for another at least six months

The criteria for exclusion from the studies were:

1. Any significant cardiovascular, neurological and orthopedic complications

2. To miss more than two weeks of the program

3. Termination on the own request or because of transplantation, presence of medical complications or death

In 2009 we conducted three studies focused on the effect of regular physical activity during hemodialysis on physical fitness and quality of life among selected patients. It was a quasiexperiment in all three cases. Randomization process was avoided because of limited number of the study participant. Also all participants were volunteers. Informal consents were sign by all participants prior the study. All of the patients were examined by a nephrology expert who approved participation in the program. Test such as Senior Fitness Test Manual [195] and hand dynamometry test [215] as well as standardized quality of life questionnaires WHOQOL-BREF [201] and KDQOL-SF36 were used for evaluation of selected parameters. HRQOL was compared to preliminary norm for the Czech population of 45 years and older $[202,203]$. So called European standard of Results for 8 components (domains) of HRQOL was used for evaluation of SF-36 questionnaire results [204, 205]. Descriptive analysis and non-parametric Wilcox signed-rank test was used for statistical analysis. Level for statistical significance was set up at $\mathrm{p} \leq 0.05$.

Following physical activity program was applied among all study participants and all described criteria and recommendations were met. Exercise intensity during hemodialysis did not exceed aerobic HR and was applied during second and third hour of hemodialysis procedure as suggested by ACSM [62] and Daul et al. [36, 49]. Exercise sessions were led by trained personnel of dialysis unit. Course of each session was in detail described at prepared protocols. Each exercise session was led individually and the personnel monitored HR, BP and sign of fatigue. Exercise was terminated in the case of decompensation or sudden worsening of health status. Maximum of three patients participated in the program at the same 
dialysis session due to organizational reasons (approximately 30 - 40 minutes of physical activity for each patient). Intensity of exercise was based on results of the three tests. The recommended intensity was always within submaximal range which is $60-70 \%$ of the maximal HR. Also objective intensity measured by Borg scale [70, 71] was monitored and did not exceed RPE of 12 - 13. Exercise sessions were performed at least two times per week. Interval form of physical loading was used for those who did not have prior physical activity experience or those who did not exercise for a long time. Also at the very beginning less number of repetitions as well as very low intensity at $30-50 \%$ of maximal HR or RPE of 7 9 was applied. Both volume and intensity were gradually increased. Periods of physical loadings were increased while rest periods were decreased; also number and used types of exercise as well as number of repetitions were increased and so forth. Very useful appeared to be an in-cooperation of relaxation and breathing exercises. Physical activity program consisted of adaptation and developing phase. Adaptation phase was performed for two months and consisted of: introduction and explanation of advantages and risks associated with physical activity in HD patients; joint flexibility training; stretching of shortened muscles; maintenance or improvement of muscle strength without use of equipment; vascular gymnastics; coordination of breathing with exercise; respiratory gymnastics; training of own body perception and body responses to exercise. Duration of each session was $20-30$ minutes. Development phase was performed for four to six months and consisted of: further improvement of adaptation phase's exercises, higher number of repetitions and extension of exercise session to $45-60$ minutes, exercise with equipment. Any complications that would harm participants were not observed.

\subsection{Overview of individual studies}

Study 1 [206]: Mixed sample of 15 hemodialysis patients participated in the study (men - N $=7$; average age $=67,9 \pm 17.8$ years; average duration of dialysis $=34$ months; women $-\mathrm{N}=$ 8 ; average age $=65.0 \pm 11.6$ years; average duration of dialysis $=32.5$ months). Functional status and QoL were evaluated before and after the intervention. Only the improvement in 2 -minutes step test among women was statistically significant $(\mathrm{p}<0.04)$ - 50\% improvement was observed. Performance on the rest of the test was improved but the results were not statistically significant. Quality of life remained the same in most of the cases. However some of the domains such "physical activity", "vitality", and "mental health" showed a tendency to improvement. Quality of life was at the bottom of healthy population norms prior the intervention. After the intervention it was close to the population average values. Improvement was observed among patients who exercised regularly.

Study 2 [207]: This study was conducted to evaluate effect of organized intradialytic physical activity on the health related quality of life among 44 hemodialysis patients (average age $=66.5 \pm 14.3$ years; average duration of dialysis $=27$ months). The majority of patients were over 60 years. From those under 60 years was 8 men (mean age $=48.5 \pm 7.2$ years) and 7 women (mean age $=49.0 \pm 11.0$ years). Quality of life was evaluated before and after the intervention. HRQOL was assessed by SF-36 and the results prior the intervention showed that the only one domain where the HD patients were comparable with the healthy population 
norms was the domain of EWB-mental health. The results of the rest of the domains were much poorer as compared to the healthy population norms. Quality of life was slightly improved after the intervention however the results were statistically insignificant.

HRQOL was assessed by WHOQOL-BREF. The domain of "physical health" was lower as compared to the healthy population norms. The rest of the domains were comparable or at least at the lower level of the normal range. The domain "mental health" improved significantly after the intervention. The improvements in the rest of the domains were observed but unfortunately the differences were not statistically significant.

In general we can conclude that the strongest tendency for improvement in SF-36 was observed in the RE "restrictions due to emotional problems", SF "social functioning", and PF "physical fitness" domains. In WHOQOL-BREF the same tendency showed only the domain "mental health". The experiences gained in the study demonstrated that in general older patients over 60 years are interested in the physical activity program participation. Between 60-75 years it was 9 men (average age $=66 \pm 4.0$ years) a 9 women (average age $=70 \pm 3.7$ years); and over 75 years it was 8 men (average age $=80 \pm 3.4$ years) a 3 women (average age $=84 \pm 4.2$ years). It was also found out that the majority of study participant had a prior experience with physical activity.

Study 3 [208]: The goal of the study was to provide comprehensive overview of ESRD, dialysis treatment, and associated complications and to present the results of the study project in the participating dialysis units in the Czech Republic. Study sample consisted of $44 \mathrm{HD}$ patients ( 25 men, average age $=66.0 \pm 14.1$ years; 19 women: average age $=67.0 \pm 14.7$ years) from three dialysis units. However data from only $27-32$ participants were analyzed. Three participants died, three had kidney transplantation and six were excluded due to worsened health status. Motor performance was analyzed among 12-16 men and 9-12 women. Those participated in both pre-tests and post-tests. HRQOL was analyzed only among 35 patients (without gender separation). Results of motor performance measured by Senior Fitness Test [195] were compared to the population norms according to age categories separately for men and women. Improvement in more than half cases was observed in men in five out of seven tests. Statistically significant improvement was observed in "chair sit and reach test" $(\mathrm{p}=0.04)$. However it is important to know that the significance might be questionable due to a low number of participants. The rest of the improvements might have not been statistically significant but it is very likely that they were important from the personal point of view (clinically significant). Women improved only in the two tests - "back scratch test" and "step-test". The improvements were observed in more than half women. HRQOL measured by SF-36 prior the intervention showed that the HD patients performed comparably with the healthy population norms except for one domain of EWB "mental health". Performance in the dimensions of PF "physical functioning", GH "general health" and RE "restrictions due to emotional problems" was significantly lower as compared to the healthy population over 45 years. Also worse performance on QoL tests was observed in the rest of the dimensions: BP "body pain", EF "vitality", RP "restrictions due to physical problems" and SF "social functioning". After the intervention some of the domains of quality of life were improved but the difference was too low so it was insignificant. 
HRQOL measured by WHOQOL-BREF showed that in comparison with the healthy population the domain of "physical health" is very poor. The lower range of the population norm was reached in the domain "mental health" prior the intervention. But after the intervention, in was significantly improved so it reached the average levels of the healthy population in the Czech Republic. In the domain "social relationships" the results before and after intervention were within the normal range. On the contrary the domain of "life conditions" was even above the normal range therefore the quality of life in this area is slightly better as compared to healthy population regardless the intervention. However the results have to be interpreted with great care due to a low number of participants.

In general it can be concluded that patients who participated in the intervention program during HD dialysis show the highest tendency for improvement in the following SF-36 domains: RE "restrictions due to emotional problems", SF "social functioning" a PF "physical functioning" and one WHOQOL-BREF domain of "mental health". Any complications that would harm participants were not observed.

Study $4,5[19,210]$ : The goal of the study was to verify the fact that motor system disorders (MSD) are also a common complication associated with ESRD in the Czech Republic and that the prevalence is higher as compared to the healthy population. Overall aim of the study was to spread general knowledge about motor system disorders among dialysis patients and to incorporate appropriate physiotherapeutic methods into complex care and therefore to improve patients' quality of life. Prevalence of MSD in healthy population was compared to the prevalence of MSD in dialysed patients. The study sample consisted of the total of 27 subjects ( 16 men/11 women, $28-86$ years, average dialysis $=44.8 \pm 53.6$ months; MSD prevalence $81.5 \%$ ).

Assessment of selected indicators was divided into three parts so duration of testing did not exceed 45 minutes. Assessment included following tests: anamnesis, kinesiology testing, stand on the two weights test, spinal functional examination, back palpation, deep stabilizing spine system examination, neurologic examination of lower extremities sensation, breathing stereotypes examination, and sit-stand test. Anamnesis data were collected using a questionnaire consisting of questions relevant to MSD. The actual selection of the questions was based on the available literature [118, 119, 216]. Questionnaire also contained questions about dialysis treatment, regular physical activity, and daily routines. Anamnesis data were then completed from the internal database of the dialysis unit and from the interview with the physiotherapist in charge. Our results were also compared with the results of international studies. The total of 26 individual (96\%) were able to walk independently at the time of testing. Out of those individuals 10 were able to walk maximally $1-4 \mathrm{~km}$ without resting. The most common complication was hypertension (21 patients, 78\%). MSD were found in 22 out of 27 subjects (81,5\%). The most common MSD was arthritis (6 patients, $22 \%$ ) and diabetic polyneuropathy (5 patients, $18,5 \%$ ). The most common symptom was pain (22 patients, $81,5 \%$ ), followed by limited ability to move and back pain (17 patients, $63 \%$ in both cases). The most damaged part of the body was spine (17 patients, $63 \%$ ).

The prevalence of MSD was significantly higher as compared to the healthy population $(\mathrm{p}<$ 0.05). Unfortunately this was thru even when comparing data of elderly population $(\mathrm{p}<$ 
0.05). Our results correspond with the results of international studies. This study was published in the two journals with different aims. One was a rehabilitation journal for strictly physiotherapy expert readers and the other one was sport science journal. In addition the results were presented at nephrology and sport congresses [209, 210, 212].

Study 6, 7, 8 [209, 212-214]: This project was focused on musculoskeletal system disorders (MSD), functional capacity and quality of the life in patients on renal dialysis treatment (RDT).The results of the study address the prevalence of MSD among HD patients.

While the first part of the project was strictly descriptive, the second part of the project was an intra-group experimental comparative study. Thus the project included two phases: diagnostic and interventional. Group 2 - ESRD patients N=67 (34 males/33 females; mean age $64 \pm 15 y r s ;$ RDT $39 \pm 56.4$ months). Aim: to prove positive effect of regular exercise program on functional and psychosocial condition of HD patients. All participants completed 6-months conditioning program during each HD. Senior Fitness Test - SFT [195] was used to evaluate functional fitness. Hand dynamometer test - Handgrip [215] was used to assess the maximum static-power capacity which is not included in SFT. We always tested non-fistula arm. To evaluate the effect of the exercise therapy, especially its influence on HRQQL, the standardized questionnaire SF-36 Bref [202] was used in the pre-tests as well as post-tests. Also so called European standard of Results for 8 components (domains) HRQOL was used [204]. Firstly we compared results of our patients with population norms and secondly we compared results of the pre- and post-tests. Descriptive analysis and non-parametric Wilcoxon signed-rank test $(\mathrm{p} \leq 0.05)$ was used to data analysis.

The number of patients decreased at the end of the study to $\mathrm{N}=49(73.1 \%$ of the original number). 18 participants ( $26.9 \%$ ) were excluded from the overall evaluation due to the following reasons: presence of significant cardiovascular, neurological and orthopedic complications; termination of the exercise program for more than two weeks; termination on the own request or because of transplantation, medical complications or death. The only statistically significant difference between pre- and post- test was observed among female group in Sit to stand test $(\mathrm{p}=0$. 04). The improvement for the rest of physical fitness tests was not found statistically significant. However $50 \%$ of the improvements ware observed in four out of seven tests. Among male group, despite the fact that none of the pre- and post- intervention differences were not found statistically significant, at least $50 \%$ of the improvements were observed in four out of seven tests. The improvement of quality of life measured by SF-36 was found statistically insignificant. There was a strong but not statistically significant increase in the two HRQOL components: RE- Emotional limitations of Roles and EV - Vitality. Based on our results, we can assume that the most important components in patients' everyday life are independence and well-being. The results of the study were published in two journals and presented at one conference. One journal is for expert medical personnel working with ESDR patients and the other deals with sport science among elderly.

Study 9 [211]: The goal of the study was to evaluate the physical fitness among randomized group of 50 individuals (19 women and 31 men, average age $54.2 \pm 11.7$ years) at early stages after the kidney transplantation (1 - 6 months). Senior Fitness Test (SFT) was used to evaluate physical fitness. The study results were compared with the population norms and with 
the results of 61 long-term hemodialysis patients (30 men, 31 women, average age $\mathbf{6 5 . 2 \pm 1 3 . 1}$ years) by statistical analysis ANCOVA. Covariate was patients' age. The group of patients after the transplantation performed better as compared to long-term hemodialysis patients (in five out of six tests $\mathrm{p} \leq 0.05$ ) but did not reach levels of healthy population.

The total of $39 \%$ patients after the transplantation were bellow or at the lower level of the population norms in overall fitness. For endurance it was $84 \%$ and for flexibility only $16 \%$. SFT proved to be an appropriated testing tool for physical fitness evaluation among renal patients at the early post-transplant stage. The SFT can be also used in the later stages for further comparisons. In addition it can be used as a motivating factor for physical activity participation.

Study 10 [214]: The goal of the study was to assess an impact of regular exercise and nutrition intervention on physical fitness and the quality of life (QoL) in the first year after kidney transplantation (Tx). Group of patients: (M/F, 11/10, age 59.1 \pm 10.8 yrs/ 57.0 \pm 8.4 yrs; $69.9 \pm 25.4 / 65.1 \pm 17.8$ days post-Tx), randomized into 4 subgroups: exercise (E), exercise + nutrition $(\mathrm{E}+\mathrm{N})$, nutrition $(\mathrm{N})$, control $(\mathrm{C})$. For testing the physical fitness and QoL we used the "Senior Fitness Test Manual" and KDQOL-SFTM questionnaire. Exercise intervention focused mainly on the joint mobility, muscle strength, nimbleness, dynamic stability, and cardio respiratory endurance (3 times/week; 60 minutes; 6 months). Nutrition intervention included substitution with keto-amino-acides. Results were analyzed using the non-parametric Wilcoxon and Kruskal-Wallis Test.

Both physical fitness as well as QoL in the first year after Tx improved in all patients. Statistically significant differences in the dynamics of physical fitness were observed in $1-4^{\text {th }}$ months post $\mathrm{Tx}$ in four out of six tests $(\mathrm{p} \leq 0.01)$ and in $1-8^{\text {th }}$ months post $\mathrm{Tx}$ in five out of six tests $(\mathrm{p} \leq 0.05)$. The greatest improvement in physical fitness was achieved by the $\mathrm{E}+\mathrm{N}$ group followed by N, E and C groups. QoL improved in the groups $\mathrm{E}+\mathrm{N}$ and $\mathrm{N}$ in seven out of eight dimensions, however the results were statistically insignificant. The combination of an exercise and nutrition intervention was the most effective.

\section{Status and further research}

Our laboratory is focused on the evaluation of physical and mental fitness of both hemodialysis patients as well as patients at early stages after kidney transplantation. Foci of our attention are effects of regular physical activity on physical fitness and quality of life of hemodialysis patients. As a result of our efforts unique intradialytic physical activity program has been developed and applied in the clinical practice. The program is among other focused on strengthening of lower extremities. It has been proven that the program is well tolerated and accepted by the majority of the patients and, most importantly, that it has a potential to improve most of the components of physical fitness and quality of life. However the improvements were not in most cases statistically significant. Negative effects were not identified. It is important to note that the results of our research studies have to be interpreted with a great care. The reasons are low research sample sizes and non-existence of control 
group. On the contrary the major goal was not to prove the changes itself but to improve life of dialysis patients by individualized care. Health status of HD patients can rapidly change due to a number of typical complications which in turn negatively affect physical fitness and thus quality of life. In accordance with available international research our studies provided additional evidence that physical activity during hemodialysis does not threaten health status of these patients. In can be concluded that positive effect of physical activity on physical fitness, especially lower extremities muscle strength, have been proven. Although the improvements of quality of life were not statistically significant it can be said that they were clinically significant and that regular physical activity has a great potential to improve quality of life, especially the domains of "physical functioning", "vitality" and "mental health". Due to advanced age of the majority of HD patients (over 60 years) it seems important to focus exercise programs on the maintenance or improvement of muscle strength since it rapidly decreases with age and the disease progress. According to ACSM [194] and Shephard [217] muscular strength decreases $15-20 \%$ per decade after 50 years. This reality negatively impacts the ability to move and to perform activities of daily living independently. Certain level of muscular strength among persons over 60 years is crucial for activities such as stair climbing, getting in and out of the public transportation or bath tub, carrying groceries, lifting objects, etc. [218]. Decreased muscle strength of lower extremities is one of the essential predictor of future locomotion problems [219, 220].

In the National Kidney Foundation Disease Outcomes Quality Initiative guidelines it is suggested that lifestyle issues such as physical activity should be seen as cornerstones of the therapy. Physical fitness in adults with chronic kidney disease (CKD) is greatly reduced so it negatively impact ability to perform activities of everyday life and occupational tasks [221].

Research studies dealing with the issue of physical activity among ESRD patients and its effect on quality of life suggest various durations of intervention programs (from 6 weeks to 4 years). However the rule "longer, better" can be applied in this case. Regarding quality of life, at least 12 weeks intervention is needed [33, 39]. The improvement is the most obvious in the domains related to physical functions. On the other hand changes in mental domains require longer interventions. Off course that the level of improvements depend on duration of the intervention, its content, volume, intensity of loading and timing with respect to hemodialysis [52]. Combination of various types of physical activity and various intensity result in greater benefits and stronger adherence to physical activity [9, 48, 52]. Adherence to physical activity of HD patients is also determined by their health status, dialysis stage, and motivation. Important factor of the success is a practical cooperation between physiotherapist and medical personnel which is well documented in number of studies $[8,39,49]$. Although advantages of intradialytic physical activity are well documented in both national and international literature, the intradialytic exercise is still quite rare in the clinical practice. Most of the early studies have been applying aerobic type of physical activity using bed-side ergometer [39, 40, 48, 50, 61, 222]. About two decades ago other types of physical activity such as joint flexibility exercises, muscle strength and endurance exercises, balance exercises, overall coordination exercises, coordination of breathing and exercise exercises or relaxation techniques started to be tested in many research projects. As mentioned earlier the goal 
of our studies was to spread the general knowledge of the benefits of physical activity among HD patients, nephrologists and physiotherapist. Selected diagnostic tools used in the international literature were proven to be appropriate for the use in the Czech Republic settings. So far physical activity programs are not an option in most Czech dialysis units although the results of our projects proved that such program are beneficial and safe. Dialysed patients have higher risk of prevalence of MSD therefore the physiotherapeutic interventions are more than appropriate. The issues of MSD among dialysis patients are not sufficiently recognized by medical care representatives. Discussed issues were very well captured by Perryman and Harwood [55] who said that painful complications of motor system limit even healthy individuals. In combination with polymorbidity of dialysis patients the presence of pain may lead to deconditioning and overall decrease of functional abilities. Physiotherapist can help dialysis patients to reach safe and long-term mobility. Thus the role of physiotherapist is in multidisciplinary care absolutely crucial [55]. The major goal of the care of motor system of dialysis patients is to ensure long-term independence and selfsupport and thus postpone the need of other person's help which at the end significantly increases the cost of care. Although the kidney transplantation is so far the most effective treatment it does not ensure immediate re- integration into ordinary life. It is important to inform patients that certain level of physical fitness is one of the most important factors influencing successful treatment [223]. The patients after kidney transplantation have better levels of fitness as compared to the patients on the dialysis but it still does not reach normal levels of healthy population. The most diminished component of physical fitness is aerobic endurance and the best is flexibility. The appropriate physical activity intervention should be a standard part of medical care of those patients. Unfortunately, with the respect to its specific requirements, it is not available type of care. The presence of someone who would lead and inform patients, monitor their health status and correct performance (type, intensity, etc.) is necessary to ensure the appropriateness of the physical activity. But needed experts such as physiologist, sport physician, rehabilitation specialist are not part of the nephrology team in the Czech Republic as well as abroad. Also commonly used tests of physical loading such as spiro-ergometry evaluations (maximal oxygen consumption, maximal heart rate, etc.) are not always appropriate for HD patients. Simple and easy to understand evaluations of physical fitness may ensure patients that the physical activity is effective and thus it can increase their motivation to remain physically active [224, 225]. SFT proved to be a great example. It is considered an alternative evaluation of physical fitness among dialysis patient although it was originally developed to assess functional fitness among elderly [195].

As already stated all study participants were volunteers. It rises a question whether the interest level in the active participation and thus the opportunity to actively influence own health can be reflected in overall QoL evaluation or not. In our opinion it certainly can. The reason for this might be an individual psychological attitude (if he/she is an optimist or pessimist), level of subjective over-estimation or under-estimation of actual health condition (at the time of testing), interest in exercise activities, etc. Patients' motivation plays an important role in QoL evaluation. The professional nursing staff must explain to HD patients the 
benefits and also potential risks of the exercise activities and to emphasize their significance for complex treatment.

As mention throughout the text regular physical activity should be essential part of active lifestyle among chronically ill dialysis patients. Appropriate exercise proved to be a great tool to improve quality of life and therefore it should be part of the complex treatment. Independence on other is desirable among all persons, especially the older ones. Physical activity participation represents an active approach in care of own body and should be always emphasized and supported. With the regard to still increasing number of older HD patients, it is important to include physical activity programs into a complex care. Equally important is to spread the knowledge about physical activity benefits in HD patients as much as possible.

\section{Practical examples of individual exercises appropriate for HD patient}

\subsection{Intradialytic Exercise Program (IEP)}

The available literatures focused on recommendation and application of physical activity program during hemodialysis procedures is sparse $[8,36,226]$. Any physical activity should be performed between $2^{\text {nd }}$ and $3^{\text {rd }}$ hour of the hemodialysis procedure. Indicators such as $\mathrm{HR}, \mathrm{BR}$ and BP should be monitor at regular intervals. The arm with a-v shunt is relaxed and lying down. This arm is not activated during the exercise. Physical activity starts slowly and the intensity, number of repetitions and exercise duration is gradually increased according to individual needs of each patient. Shorter exercises are preferred at the early stages of intervention. Patients should wear comfortable clothing. It is recommended not to eat at least one hour prior the exercise session (excluding diabetics). Recommended drinking depends on the amount of urination. It appears to be useful to set up individual goal before each exercise session (for example to learn two new exercises and repeat those five times or to climb stairs instead of using elevator). After mastering the goal a new more challenging goal should follow. All exercises should be performed slowly with great concentrations while strictly maintaining proper position. Important is a regular breathing without holding it in. It is useful to remind patients who are not used to physical activity that exercise is often accompanied by muscle pain, joint pain and muscle fatigue, especially on the day after the exercise session. Those symptoms are not very common right after the session and sometimes they can be postponed for another few days. There is no need to worry. The body is adapting to exercise so the symptoms become less and less obvious until they disappear completely. Important is not to terminate regular exercises because every start is hard. It is recommended to perceive exercise as a pleasant addition to daily routines. Individual exercises are selected according to patients' preferences. Pain should not be suppressed at any time. Whole process of exercise session should be documented in prepared protocols. Also resting days should be monitored together with the reason of inactivity. Filled up protocols are important for the feedback which is necessary for the future physical loading plan. All earlier mentioned indicators (HR, BR and BP) are continuously monitored during physical activity session and all eventual deviations to normal conditions are documented. Prior the 
beginning of the exercise, patients are provided with information about actual content of the session and factors leading to the exercise termination. Patients are again reminded not to use the arm with a-v shunt. It is recommended to perform few exercises using this arm after the dialyses although the area of a-v shunt should be always avoided. Equipment such as light balls or overballs are suitable for loading the a-v shunt arm. The exercise should be slowed down when patient experiences any of the following symptoms: difficulties with breathing, lack of breath, heavy perspiration, abnormally high HR (or abnormally low HR). Exercise should be avoided on very hot or humid days or when patients do not feel well. Cramps, muscle pain or abnormal feeling one hour after the session signalize too challenging exercise. In that case the exercise is immediately terminated. If symptoms such as dizziness, nausea, cramps, serious fatigue, chest pain, irregular HR are presented, physician in charge should be contacted.

Good physical fitness is a prerequisite for promoting good quality of life and can prolong survival of hemodialyzed patients. The beneficial effect of regular physical activity on the overall fitness and mental status of hemodialyzed patients has been reviewed in detail in a number of studies [21-43,221]. Specific benefits of regular exercise in hemodialysis include:

- in terms of physical fitness: increased exercise tolerance; improved overall functional status of the motor system; normalization of the lipid profile (HDL cholesterol, triglycerides, and so on); normalization of insulin tolerance and metabolism; power training muscle protein synthesis and inhibition of protein catabolism; improved hypertension control $\rightarrow$ reduction of the risk factors of cardiovascular complications and their decreased incidence $\rightarrow$ reduced morbidity and mortality rates.

- in terms of psychological fitness: improved control of depression and anxiety; improved mood, self-confidence; improved management of sleep disorders; improved nutrition and appetite; improved adaptation to stress, workload, and out-of-work activities; improved social interaction, support of return to work and improved social interaction; reduced dependence on others.

The mainstay of our intradialytic exercise program are activities leading to maintenance or improvement of joint flexibility and muscular strength, compensation of muscle disbalances (overloading and shortening of muscle groups), renovation of dynamic stereotypes necessary for independent living, correction of muscle coordination disorders, and improvement of cardio-respiratory fitness.

Individual exercises and variants thereof have been developed so they can be readily performed during hemodialysis. Long-term repetition and extension of the main part of the physical activity session will help improve the above components of physical fitness. By offering the patient a chance to maintain or improve their physical fitness, active elimination of musculoskeletal system-related complaints makes the patient aware of their independence and self-sufficiency as well as their potential contribution to promoting their physical and mental health and improving their quality of life.

Joint mobility (flexibility) is a physical feature whose development affects a man's functional capacity. As regards performance of physical activities, flexibility is a variable characterizing 
the status of the muscular system and, in combination with other variables, characterizes a body's functional status [227]. Joint mobility is closely associated with the status of the muscular system or, more exactly, with balanced muscle stretching and strengthening referred to as muscle balance. A shortened muscle or a muscle group may restrict the extent of joint movement. A certain extent of joint mobility is critical for proper performance of a movement and may also affect muscle strength. Weakened muscles are unable to move properly through the desired movement pattern, which is why ancillary muscles become involved in the movement and may subsequently become unnecessarily overloaded. Adequate muscle strength is crucial for maintaining or strengthening a patient's current movement ability and skills. Muscle strength can be obtained or enhanced by power exercise. Special attention should primarily be given to strengthening weakened muscle groups or those showing a tendency to wasting (phasic muscles, e.g., abdominal, gluteal muscles). While muscle strengthening is of critical importance for the elderly, muscle strength is a factor limiting self-sufficiency and self-care not only in that particular patient population. Attention should be given to strengthening of lower limb muscles but, also, of all muscle groups as a whole. Before starting a program of strengthening weakened muscle groups and during it, consideration should also be given to stretching muscle groups with a tendency to shorten, and those with a higher resting tone to maintain the upright posture. Balanced stretching and strengthening of muscles based on their tendency to shorten or waste will not only contribute to developing and maintaining their current abilities and skills as well as enhancing the level of self-care and self-sufficiency, it will also prevent the development of so-called muscle imbalance experienced by most - not only those suffering from chronic disease or elderly - patients. When performing individual exercises, emphasis should always be placed on the respiratory phase. Proper coordination of movements and breathing is critical not only for the correct performance of a movement but, also, for adequate oxygen supply to the working muscle.

\subsection{Example of intradialytic physical activity session [228]}

Our exercise program gives only several examples of exercises that can be helpful in developing components of physical fitness. The exercises have been selected from a large set of exercises designed for the hemodialysis patient. The whole exercise set along with the respective illustrations is available in a publication [228] by Svoboda and Mahrová (2009).

Characteristics of individual phases are presented below. Individual exercises are focused on upper or lower extremity movements (arms or legs) separately. All exercises can be combined using arms and legs at the same time. When combining the exercises, coordination of all movements becomes more difficult, therefore, the focus on proper execution is crucial.

The defined number of repetitions is recommended, however, it does not have to be strictly followed. Adjusting the repetitions according patients' subjective feeling during the exercises is recommended. The exercise unit may start with lower number of repetitions, which may be gradually increased with respect to the enhanced fitness.

Starting position (the position the exercise starts with) - SP 


\section{Warming-up:}

1. SP: Back-lying position, arms are alongside the body.

Movements: Wrist circling, alternately in both directions. See Figure 1.

Repetitions: 6-8 times to the right, then to the left, separately.

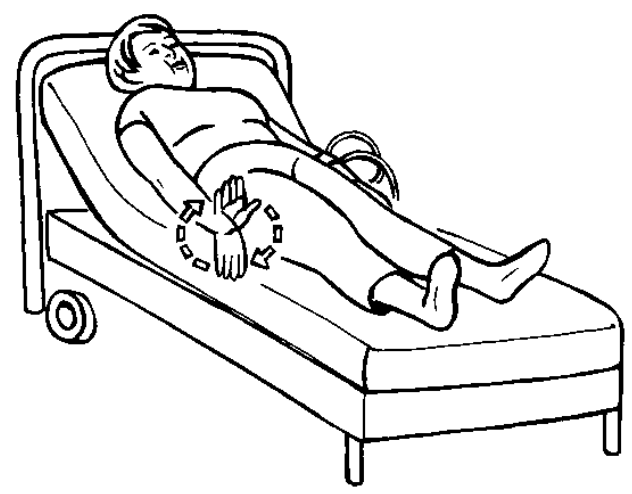

Figure 1.

2. SP: Back-lying position, arms are alongside the body with palms facing upward.

Movements: While breathing out, bend your arms at the elbows with palms touching the shoulders. See Figure 2.

Repetitions: 6-8 times

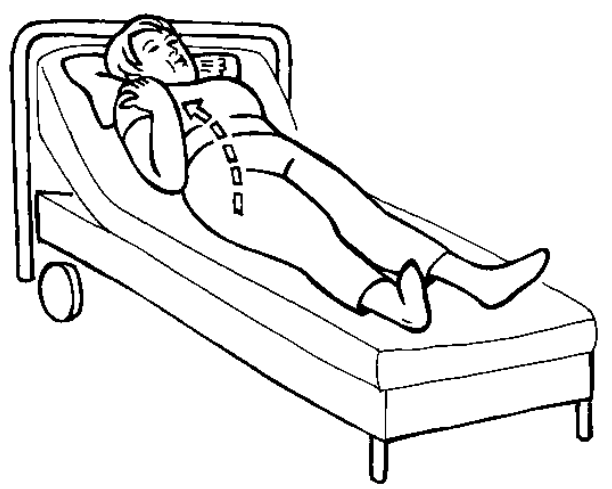

Figure 2.

3. SP: Back-lying position, the arms is flexed with palm on the shoulder („wing“). 
Movements: Shoulder circling, alternately in both directions. The shoulder of the arm with the AV- fistula performs circling while adducted. Note: Do not hold the breath. The arm moves upward while breathing in, and downward while breathing out. See Figure 3.

Repetitions:6-8 times

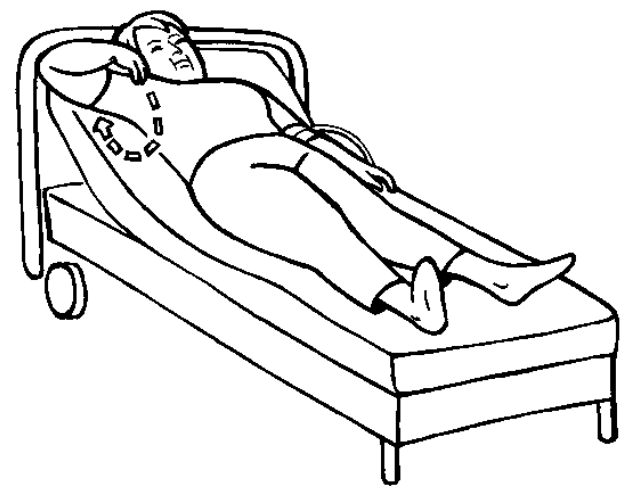

Figure 3.

4. SP: Back- Repetitions: lying position, legs are hip-width apart, arms alongside the body.

The goal: Vascular gymnastics - supports blood circulation in deep veins.

Movements: Flex the tips of your feet towards the shins, breathe out, stretch the tips and breathe in. Alternative: Alternately flexing and stretching the tips of the feet. See Figure 4.

Repetitions: 6-8 times

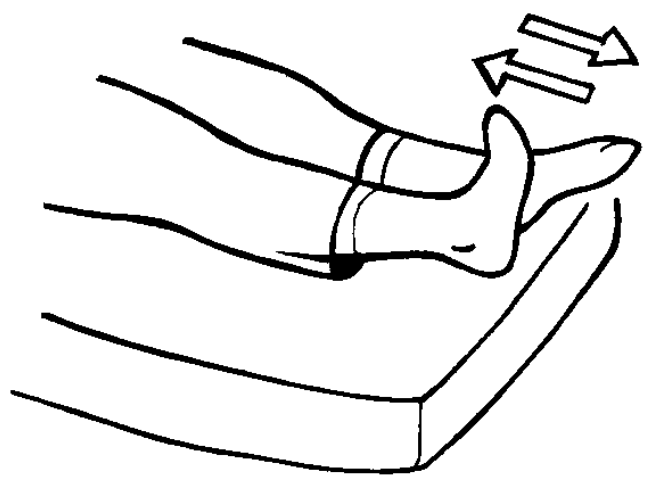

Figure 4. 
5. SP: Back-lying position, arms are alongside the body.

Movements: Bend the knees alternately, breathe in, go back to the starting position and breathe out.

Note: Do not hold the breath. Do not bend both knees at the same time.

Alternative: Bend your knees, breathe in, stretch your legs upward, breathe out, bend your knees again, breathe in, go back to the starting position while breathing out (,triple-flexion“). See Figure 5a, 5b.

Repetitions: 6-8 times

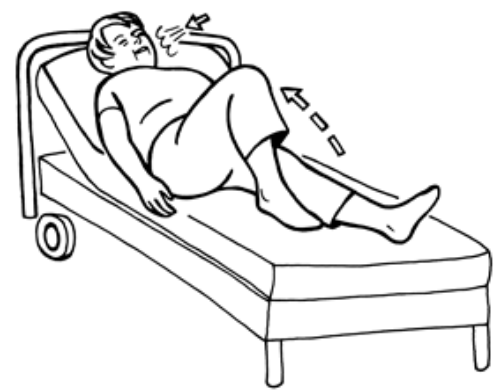

(a)

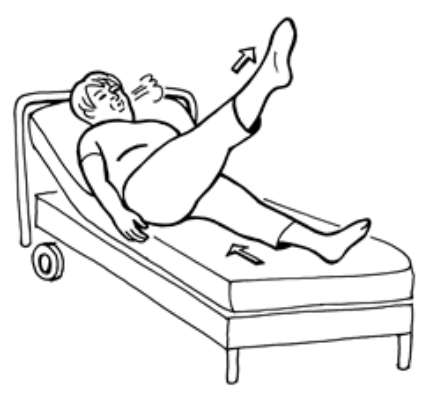

(b)

Figure 5.

6. SP: Back-lying position with knees bent, arms are alongside the body.

Movements: Keep your lower back flat on the floor while breathing out, legs alternately perform the bike riding movements. Alternately use the right and left leg. Note: Do not hold the breath. Do not sag. See Figure 6.

Repetitions: 6-8 times

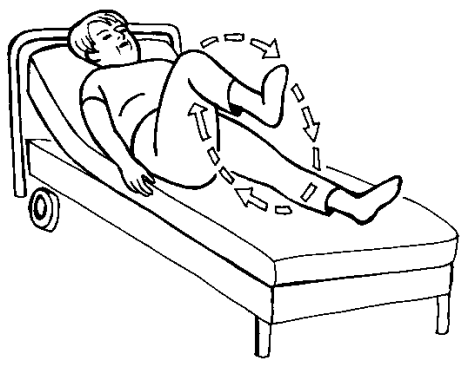

Figure 6. 


\section{Main Part:}

The main part can be divided into three individual sections focused on increasing the joint range movement, stretching and strengthening part. Execute the joint range movement enhancing exercises only when the movement is felt comfortable. Do not exercise against the pain. The stretching exercises should be associated with the feeling of comfortable muscle pull, never do the exercise against the pain. The strengthening exercises should be executed slowly with gradual muscle pull that is felt comfortable. Aids: Thera-Bands® (various flexibility, yellow, red, green and blue thera-bands are recommended), physio-big ball, overball, small soft balls, dumbbells $(0.5 \mathrm{~kg}, 1 \mathrm{~kg}, 2 \mathrm{~kg})$.

Enhancing Joint Range Movements - the exercises are the same as those used in the warmingup phase, the number of repetitions is higher.

\section{Muscle Stretching}

\section{Muscle group: Muscles of the whole body}

SP: Back-lying position, arms are alongside the body.

Movements: Stretch your arms upward, reach out, breathe in, release and breathe out. Alternative: Alternately stretch diagonally just one leg and one arm. Note: Do not hold the breath. Do not sag. Do not lift your shoulders. See Figure 7.

Repetitions: 6-8 times

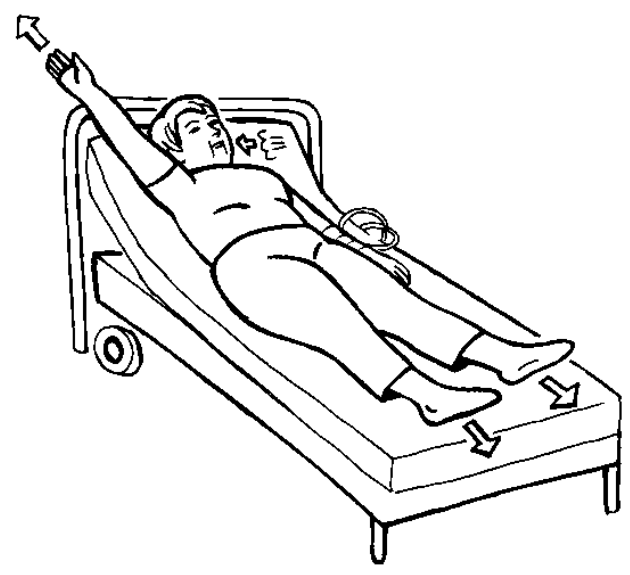

Figure 7.

\section{Muscle group: Neck extensors}

SP: Back-lying position, knees are flexed with feet flat on the floor, arms are alongside the body. 
Movements: Breathe in, stretch your neck and head in line with the neck spine while breathing out, the chin is pressed towards the chest ("double chin"). Note: Head rests on the floor or on a pillow. See Figure 8.

Repetitions: $2-4$ times, hold the stretched position for $10-15$ seconds.

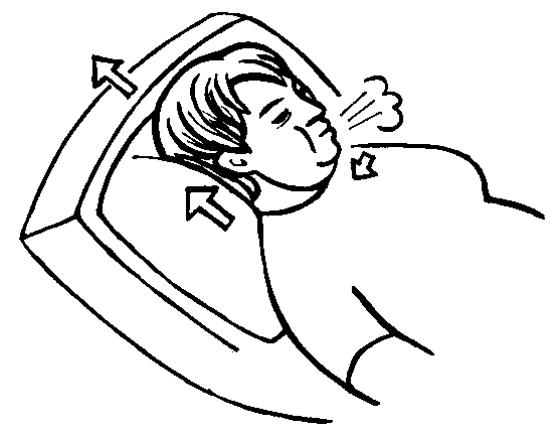

Figure 8.

3. Muscle group: Neck muscles - trapezius muscles

SP: Back-lying position, knees are flexed with feet flat on the floor, arms are alongside the body, shoulders pushed downward.

Movements: Breathe in, and while breathing out tilt your head by sliding the head on the floor alternately to the right and left. The ear is pulled towards the shoulder, shoulders are pushed downward. You must feel the muscle pull beginning below the ear through the neck towards the shoulder on the stretched side of the body. Note: Do not turn the head to the side. See Figure 9.

Repetitions: $2-4$ times, hold the stretched position for $10-15$ seconds.

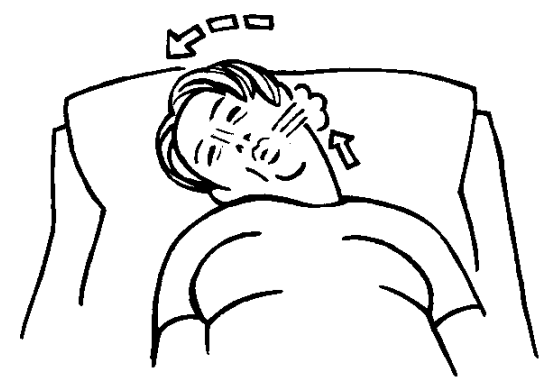

Figure 9. 
4. Muscle group: Gluteal muscles, muscles on the back of the thigh

SP: Back-lying position

Movements: One leg is flexed at the knee, arms clasp below the knee as you breathe out, the leg is pulled towards the chest. The other leg reaches out as much possible while remaining on the floor. Return to the starting position while breathing in, perform the same to the other side. Note: Do not pull the leg using the arm with the A-V fistula, do not hold the breath, do not lean your head backward, and do not lift your legs off the floor. See Figure 10.

Repetitions: 2 - 4 times, hold the stretched position for $10-15$ seconds.

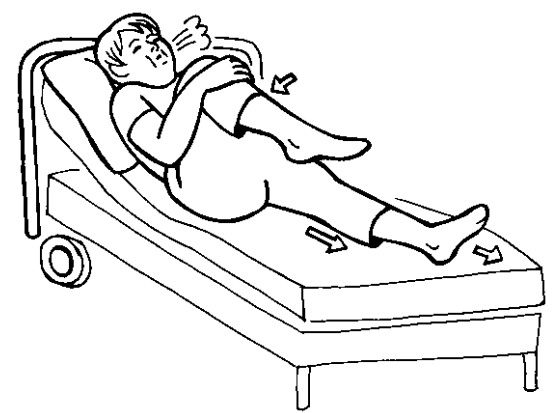

Figure 10.

5. Muscle group: Gluteal muscles, outer thigh muscles, low back

SP: Back-lying position, legs are flexed and crossed, arms are alongside the body, slightly to the sides.

Movements: Breathe in and while breathing out, tilt both legs to the side, alternately to the right and left. Note: Scapulas remain flat on the floor, do not lean your head backward, do not sag, do not hold the breath. See Figure 11.

Repetitions: 2 - 3 times, hold the stretched position for 10 - 15 seconds.

6. Muscle group: Spinal erectors, deep muscles of the back (rotators)

SP: Back-lying position, arms are alongside the body.

Movements: Breathe in, put your right leg across the left while your head to the opposite side and breathing out. The lower leg is supported against the left thigh, the left arm is supported against the outer side of the right thigh. Alternate the left and right leg.

Note: Scapulas remain flat on the floor. See Figure 12.

Repetitions: $2-4$ times, hold the stretched position for $10-15$ seconds. 


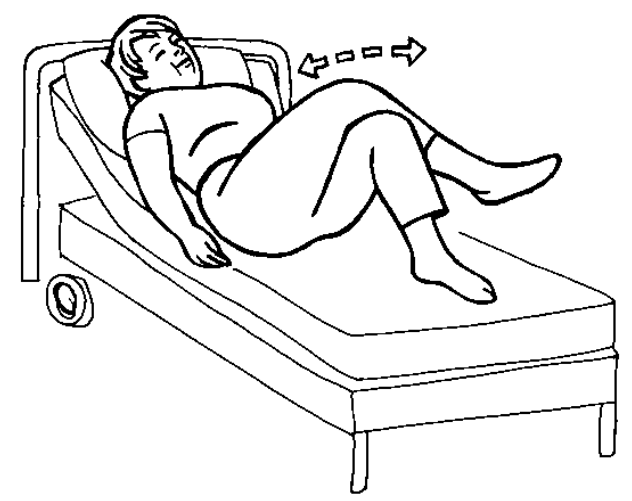

Figure 11.

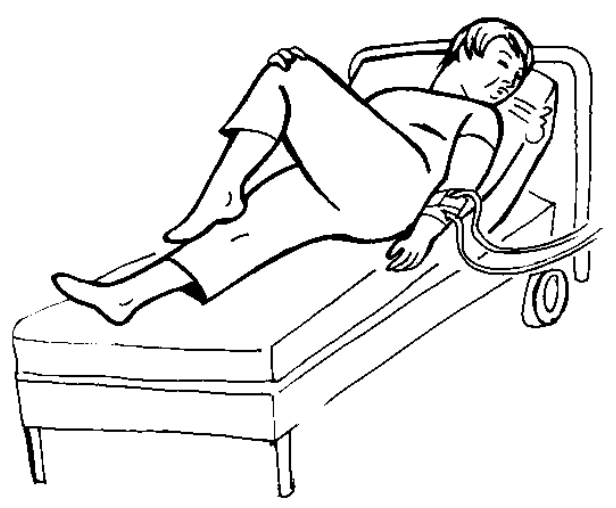

Figure 12.

7. Muscle group: Inner thigh muscles

SP: Back-lying position, knees are flexed with feet flat on the floor, arms are alongside the body or stretched to the side.

Movements: Breathe in, lower your knees to the side towards the floor while breathing out, soles remain connected. Note: Do not hold the breath. Do not sag. See Figure 13.

Repetitions: $2-4$ times, hold the stretched position for $10-15$ seconds. 


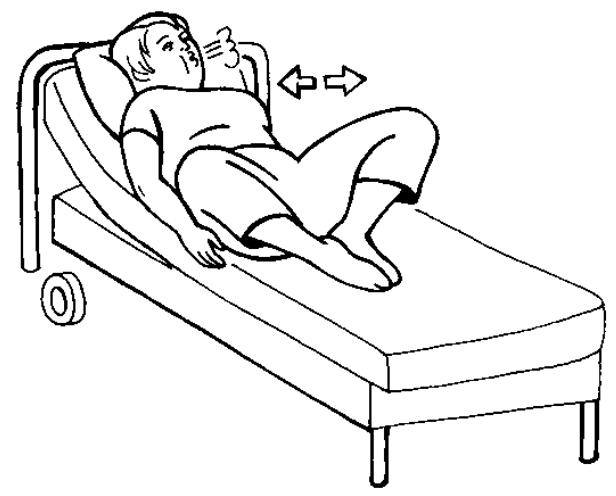

Figure 13.

\section{Muscle strengthening}

\section{Muscle group: Straight abdominal muscles}

SP: Back-lying position, knees are flexed with feet flat on the floor, arms are alongside the body.

Movements: Tighten your abdominals while breathing out, keep your low back flat on the floor, lift your head, shoulders and scapulas up from the floor, push your shoulders downward, tips of the feet are flexed towards the shins, look above your knees to the distance. See Figure 14. Note: Do not hold the breath. If your abdominal muscles are weak, lift your head only, scapulas are flat on the floor.

Repetitions: 6-8 times, hold for 2-3 seconds.

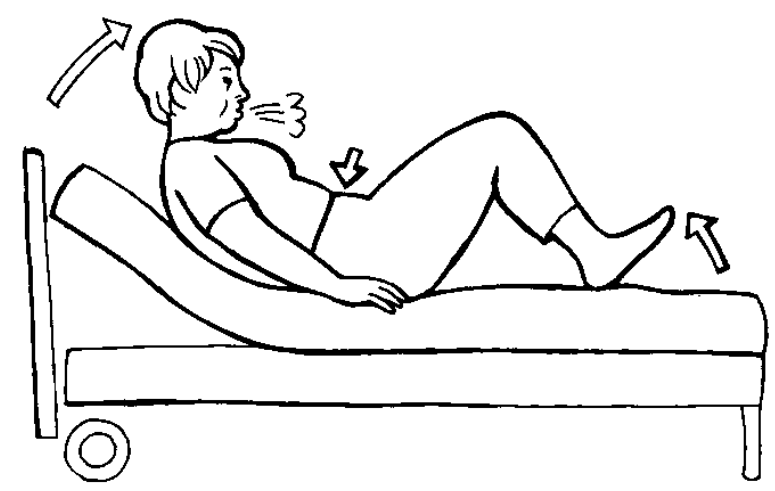

Figure 14.

2. Muscle group: Straight abdominal muscles 
SP: Back-lying position, legs are bent approximately at 90 degrees at the hip and knee joints, the little ball is on your lower legs, arms are alongside the body.

Movements: Roll the ball on your lower legs back and forth, breathe regularly. See Figure 15. Note: Use only soft, small balls.

Repetitions: 6-8 times.

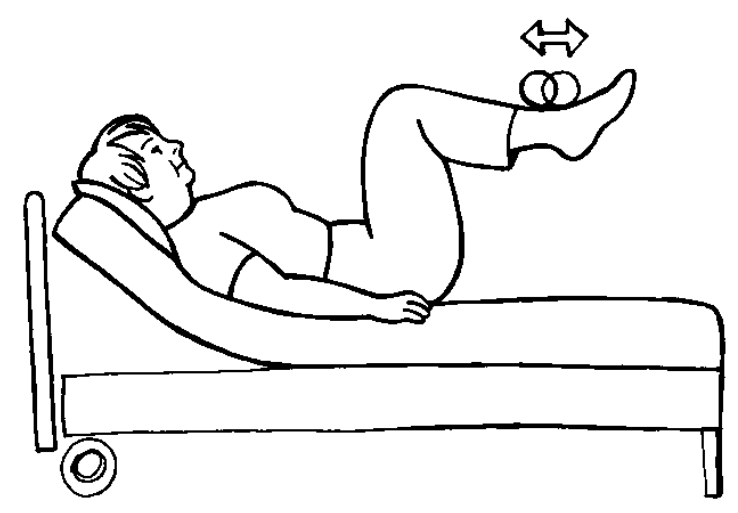

Figure 15.

3. Muscle group: Muscles of the back of the thigh, gluteal muscles

SP: Back-lying position, knees are flexed with feet flat on the floor, arms are alongside the body with palms facing the floor.

Movements: Tighten your glutes while breathing out, low back is flat on the floor, continue with lifting your low back from the floor, slowly, vertebra by vertebra up to the scapulas, breathe in, and gradually go back to the starting position while breathing out. Alternative: The movement can be divided into 2, 3 phases, hold the muscle contraction. See Figure 16.

Note: Do not hold breath, the movement is executed slowly with slight arm support.

Repetitions: 5-8 times, hold for 2-3 seconds. 


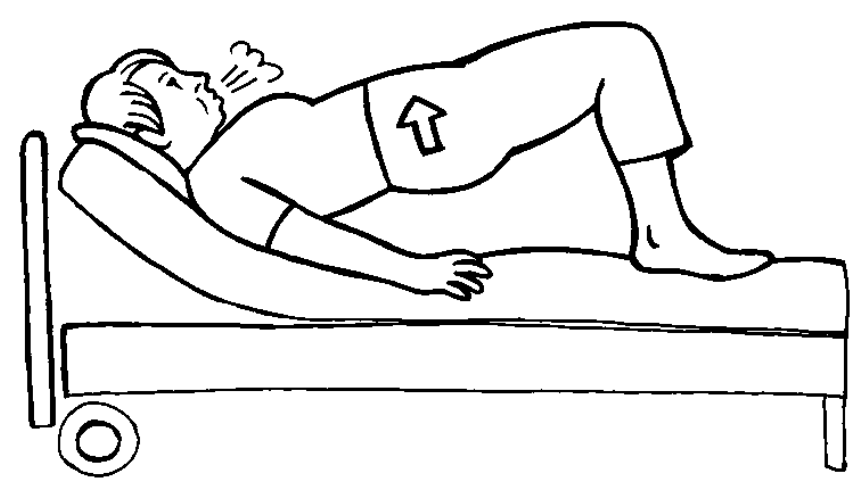

Figure 16.

\section{Muscle group: Outer thigh muscles}

SP: Back-lying position, knees are slightly flexed, arms alongside the body. The Thera Band ${ }^{\circledR}$ is above the ankles.

Movements: While breathing in, slightly lift one leg off the floor and tilt the leg to the side while breathing out. Repeat the same with the other leg. Alternative: The movement can be divided into 2-3 phases, with hold of the muscle contraction. See Figure 17.

Note: Knees can be supported by a roll, or a rolled mat. Low back is flat on the floor. To ensure the leg is tightened, flex the tip of the exercised leg towards the shin.

Repetitions: 6-8 times.

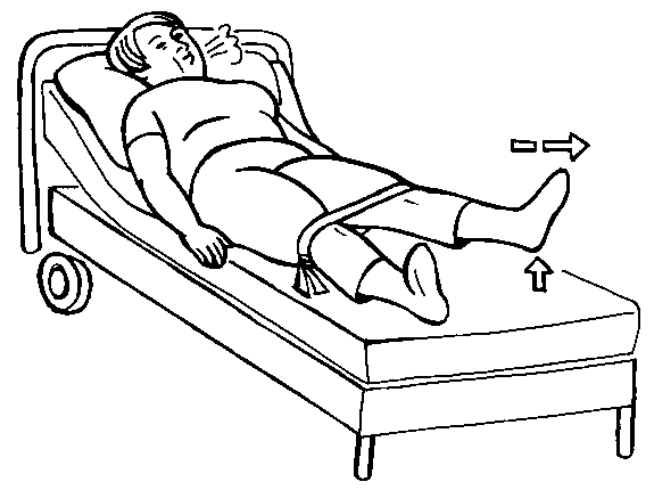

Figure 17.

5. Muscle group: Inner thigh muscles 
SP: Back-lying position, knees are slightly flexed, arms alongside the body. Put an overball or a rolled blanket in between your knees.

Movements: While breathing out push the knees and thighs toward each other, release while breathing in. Note: Knees can be supported by a roll, or a rolled mat. The arm with the AV fistula must not press against the floor. See Figure 18.

Repetitions: 6-8 times.

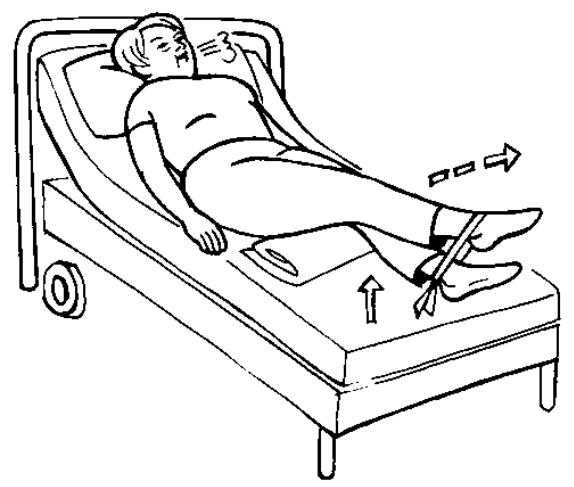

Figure 18.

6. Muscle group: Hip flexors, front thigh muscles

SP: Back-lying position, knees are slightly flexed, arms alongside the body. The Thera Band $\AA$ is above the ankles.

Movements: Lift one leg off the floor while breathing out, perform the same with the other leg. Note: Knees can be supported by a roll, or a rolled mat. The arm with the AV fistula must not press against the floor. See Figure 19.

Repetitions: 6-8 times.

7. Muscle group: Shoulder girdle muscles

SP: Back-lying position, knees are slightly flexed with feet flat on the floor, arms alongside the body. The Thera - Band $\AA$ is attached to the bedside or an armchair.

Movements: While breathing out, the arms raise and pull the Thera-band up and forward, release while breathing in. Alternative: The movement can be divided into 2-3 phases, with hold of the muscle contraction. See Figure 20.

Repetitions: 6-8 times. 


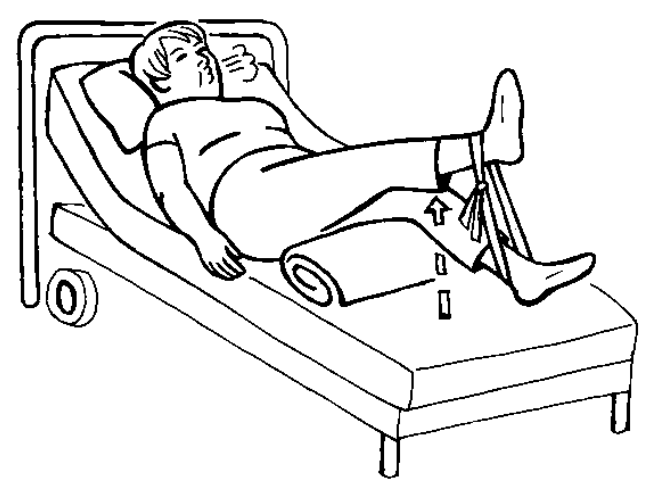

Figure 19.

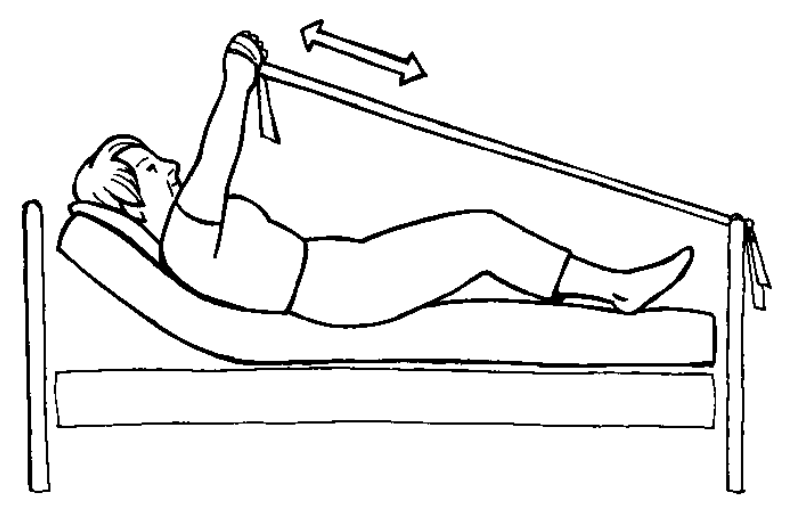

Figure 20.

8. Muscle group: Outer shoulder muscles

SP: Back-lying position, knees are flexed, arms alongside the body. The Thera -Band ${ }^{\circledR}$ is attached to the bedside or an armchair.

Movements: One arm (the one without the A-V fistula) is stretched to the side at the shoulder height. The arm slides on the floor. Alternative: The movement can be divided into 2-3 phases, with hold of the muscle contraction. See Figure 21.

Repetitions: 6-8 times. 


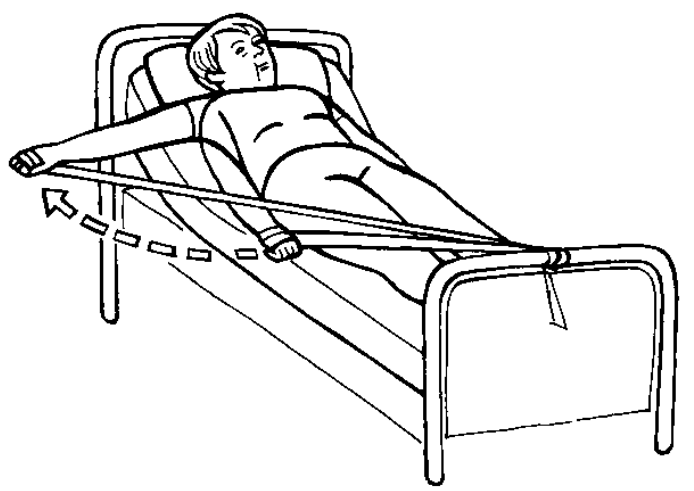

Figure 21.

9. Muscle group: Latissimus dorsi, rotator cuff muscles

SP: Back-lying position with knees flexed, one arm (the one without he A-V fistula) is raised upward. The Thera - Band ${ }^{\circledR}$ is attached to the bedside or an armchair.

Movements: The arm pulls the Thera-Band down from the upward to the forward position. Alternative: The movement can be divided into 2-3 phases, with hold of the muscle contraction. See Figure 22.

Repetitions: 6-8 times.

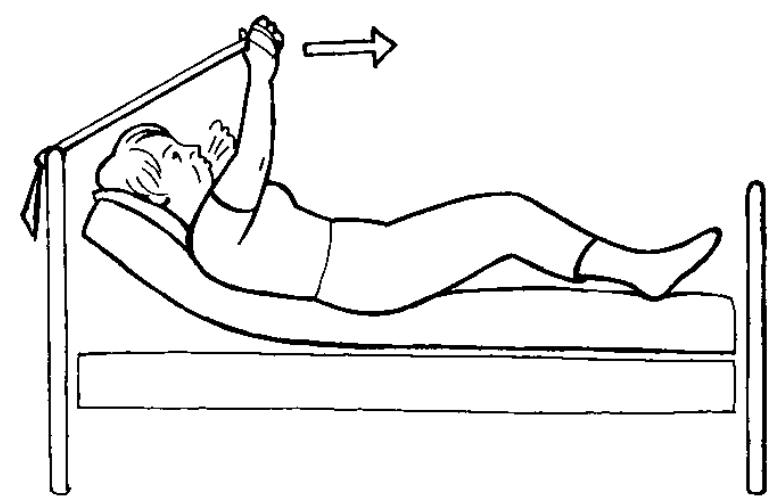

Figure 22.

10. Muscle group: Biceps 
SP: Back-lying position, knees are slightly flexed with feet flat on the floor; arms are alongside the body with palms facing upward. The Thera -Band ${ }^{\circledR}$ is attached to the bedside or an armchair.

Movements: Flex your arm at the elbow while breathing out and go back to the starting position while breathing in. Alternative: The movement can be divided into 2-3 phases, with hold of the muscle contraction. See Figure 23.

Note: The upper arm remains in contact with the floor.

Repetitions: 6-8 times.

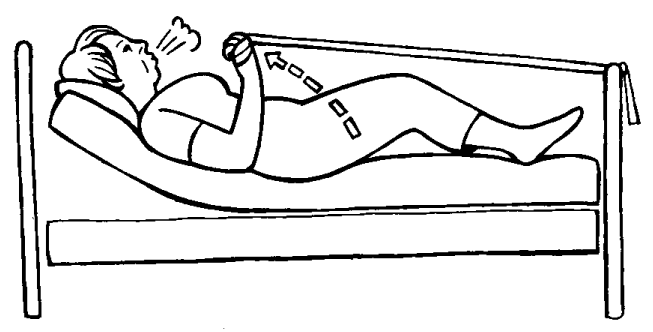

Figure 23.

The Final part:

The final part should be focused on stretching the exercised muscle groups. Complementing this part with some relaxation music is beneficial and recommended. Heart rate should be taken at the end of the exercise following the cool-down phase. The heart rate should be approximately the same as before starting the exercise, which corresponds to a normal resting heart rate.

\section{Acknowledgements}

This chapter was financially supported by the project GACR P407/12/0166.

\section{Author details}

Andrea Mahrova* and Klara Svagrova

*Address all correspondence to: mahrova@centrum.cz

Faculty of Physical Education and Sports Charles University in Prague, Sports Research Centre, Prague, Czech Republic 


\section{References}

[1] Mahrova A, Bunc V, Fischerova H. Motor skills testing in patients with chronic renal failure. Cas Lek Cesk 2006;145(10) 782-7.

[2] Sulkova S, et al. Hemodialýza (CZ). Praha: Maxdorf; 2000.

[3] Johansen KL. Physical functioning and exercise capacity in patients on dialysis. Adv Ren Replace Ther 1999;6(2) 141-8.

[4] Lundin AP, et al. Cardiovascular status in long-term hemodialysis patients: an exercise and echocardiographic study. Nephron 1981; 28 234-237.

[5] Kenny A, et al. Effects of hemodialysis on coronary blood flow. Am J Cardiol 1994; 74(3) 291-294.

[6] Foley RN, et al. Cardiovascular disease in chronic renal disease: Clinical epidemiology of cardiovascular disease in chronic renal disease. Am J Kidney Dis 1998; Suppl 3, 32(5) 112-119.

[7] Deligiannis A, Kouidi E, Tassoulas E, et al. Cardiac response to physical training in hemodialysis patients: an echokardiographic study at rest and during exercise. Int J Cardiol 1999; 70(3) 253-66.

[8] Fuhrmann I, Krause R. Principles of exercising in patients with chronic kidney disease, on dialysis and for kidney transplant recipients. Clin Nephrol 2004; 61 (Suppl 1) 14-25.

[9] Kouidi EJ. Central and peripheral adaptations to physical training in patiens with end-stage renal disease. Sports Med 2001; 31(9) 651-665.

[10] Colangelo RM, Stillman, MJ, Kessler-Fogil D. The role of exercise in rehabilitation for patients with end-stage renal disease. Rehabil Nurs 1997; 22(6) 288-92, 302.

[11] Teplan V. Praktická nefrologie. Praha: Grada Publishing; 1998.

[12] Teplan V. Metabolismus a ledviny. Praha: Grada Publishing; 2000.

[13] Kouidi E, et al. The effects of exercise training on muscle atrophy in hemodialysis patients. Nephrol Dial Transplant 1998; 13(3) 685-699.

[14] Pianta TF. The role of physical therapy in improving physical functioning of renal patients.Adv Ren Replace Ther 1999;6(2)149-58.

[15] Tawney KW, et al. The life readiness program: A physical rehabilitation program for patients on hemodialysis. Am J Kidney Dis 2000; 36(3) 581- 591.

[16] Mercer TH, et al. Nutritional status, functional capacity and exercise rehabilitation in end-stage renal disease. Clin Nephrol 2004; 61 (Suppl 1) 54-59.

[17] Davison SN. Pain in hemodialysis patients: prevalence, cause, severity, and management. AM J Kidney Dis. 2003 Dec;42(6) 1239-47. 
[18] Jurova K, Mahrova A, Bunc V. Movement system disorders in dialysed patients. Rehabilitacia (SK). 2009;46(2):76-86.

[19] Jurova K., Mahrova, A., Bunc, V. Functional Investigation of Musculoskeletal System in Hemodialysis Patients. Rehabilitacia (SK) 2009; 46(3) 155-163.

[20] Bourbonnais FF, Tousignant KF. The pain experience of patients on maintenance hemodialysis. Nephrol Nurs J 2012; 39(1) 13-9; quiz 20.

[21] Kouidi E, et al. Exercise renal rehabilitation program: Psychosocial effects. Nephron 1997; 77(2) 152-58.

[22] Bommer J. Medical complications of the long-term dialysis patient. In: Cameron S, et al. Oxford textbook of clinical nephrology. New York: Oxford University Press; 1992.

[23] Ilic S, et al. Psychological defense mechanisms of patients with end-stage kidney disease as adaptation factor to hemodialysis treatment. Int J Artif Org 1997; 20(10) 545-546.

[24] Jurke PV. Ansätze der Körpererfahrung und des Körpersbewusstseins. In: Daul AE, et al. Sport- und Bewegungstherapie für chronisch Nierenkranke. Munchen: Dustri Verlag; 1997.

[25] Jetté $M$, et al. Effects of an exercise programme in a patient undergoing hemodialysis treatment. J Sports Med Phys Fitness 1977; 17(2) 181-186.

[26] Gutman R, et al. Physical capacity and employment status in patients on maintenance dialysis. Engl J Med 1981; 304(6) 309-313.

[27] Zabetakis PM, et al. Long-duration submaximal exercise conditioning in hemodialysis patients. Clin Nephrol 1982; 18(1) 17-22.

[28] Carney RM, et al. Psychological effects of exercise training in hemodialysis patients. Nephron 1983; 33(3) 179-181.

[29] Goldberg AP, et al. Therapeutic benefits of exercise training for hemodialysis patients. Kidney Int Suppl. 1983; 16:S 303-309.

[30] Hagberg JM, et al. Exercise training improves hypertension in hemodialysis patients. Am J Nephrol 1983; 3(4) 209-212.

[31] Painter P, Zimmermann SW. The role of exercise in the long therm rehabilitation of patients with end stage renal disease. AANNT J 1983; 10(6) 41-46.

[32] Carney RM, Templeton B, Hong BA, Harter HR, Hagberg JM, Schechtman KB, Goldberg AP. Exercise training reduces depression and increases the performance of pleasant activities in hemodialysis patients. Nephron 1987; 47(3) 194-198.

[33] Daul AE, et al. Dialyse - Sportgruppe: Eine Möglichkeit zur Verbesserung der körperlichen Leistungsfähigkeit und der psycho-sozialen Rehabilitation chronischer Dialysepatienten. Nieren- und Hochdruckkrankh 1990; 19 279-286. 
[34] Clyne N, Ekholm J, Jogestrand T, Lins LE, Pehrsson SK. Effects of exercise training in predialytic uremic patients. Nephron 1991; 59(1) 84-89.

[35] Kutner NG, Lin LS, Fielding B, Brogan D, Hall WD. Continued survival of older hemodialysis patients: investigations of psychosocial predictors. Am J Kidney Dis 1994; 24(1) $42-49$.

[36] Daul AE, et al. Sport- und Bewegungstherapie für chronisch Nierenkranke. Munchen: Dustri - Verlag; 1997.

[37] Castaneda C, Grossi L, Dwyer J. Potential benefits of resistance exercise training on nutritional status in renal failure. J Ren Nutr 1998; 8(1) 2-10.

[38] Painter P, Carlson L, Carey S, Paul SM, Myll J. Physical functioning and health-related quality of life changes with exercise training in hemodialysis patients. Am J Kidney Dis 2000; 35(3) 482- 492.

[39] Oh-Park M, Fast A, Gopal S, Lynn R, Frei G, Drenth R, Zohman L. Exercise for the dialyzed - Aerobic and strenght training during hemodialysis. Am J Phys Med Rehabil 2002; 81(11) 814-821.

[40] Kouidi E, Grekas D, Deligiannis A, Tourkantonis A. Outcomes of long-term exercise training in dialysis patients: comparison of two training programs. Clin Nephrol 2004; 61 (Suppl 1) 31-38.

[41] Yurdalan SU, Kondu S, Malkoç M. Assessment of health-related fitness in the patients with end-stage renal disease on hemodialysis: using Eurofit Test Battery. Ren Fail 2007; 29(8) 955-60.

[42] Segura-Ortí E, Rodilla-Alama V, Lisón JF. Physiotherapy during hemodialysis: results of a progressive resistance-training program. Nefrologia 2008; 28(1) 67-72.

[43] Ouzouni S, Kouidi E, Sioulis A, Grekas D, Deligiannis A. Effects of intradialytic exercise training on health-realated quality of life indices in haemodialysis patients. Clin Rehabil, 2009; 23(1) 53-63.

[44] Oliveros R MS, Avendaño M, Bunout D, Hirsch S, De La Maza MP, Pedreros C, Müller H. A pilot study on physical training of patients in hemodialysis. Rev Med Chil 2011 ; 139(8) 1046-53.

[45] Couto CI. Exercise training improves cardiovascular fitness in people receiving haemodialysis for chronic renal disease. J Physiother 2012; 58(2) 130.

[46] Orcy RB, Dias PP, Seus TL, Barcellos FC, Bohlke M. Combined Resistance and Aerobic Exercise is Better than Resistance Training Alone to Improve Functional Performance of Haemodialysis Patients - Results of a Randomized Controlled Trial. Physiother Res Int. 2012; Jun 13. doi: 10.1002/pri.1526. [Epub ahead of print].

[47] Samara AP, Kouidi E, Ouzouni S, Vasileiou S, Sioulis A, Deligiannis A. Relationship between exercise test recovery indices and psychological and quality-of-life status in 
hemodialysis patients: a pilot study. J Nephrol. 2012; Jun 15 :0. doi: 10.5301/jn. 5000144. [Epub ahead of print].

[48] Konstantinidou E, Koukouvou G, Kouidi E, Deligiannis A, Tourkantonis A. Exercise training in patients with end-stage renal disease on hemodialysis: comparison of three rehabilitation programs. J Rehabil Med 2002; 34(1) 40-45.

[49] Daul AE, Schäfers RF, Daul K, Philipp T. Exercise during hemodialysis. Clin Nephrol. 2004; 61 (Suppl 1) 26-30.

[50] Shalom R, Blumenthal JA, Williams RS, McMurray RG, Dennis VW. Feasibility and benefits of exercise training in patients on maintenance dialysis. Kidney Int. 1984; 25(6) 958-963.

[51] Williams A, Stephens R, McKnight T, Dodd S. Factors affecting adherence of endstage renal disease patients to an exercise programme. Br J Sports Med 1991; 25(2) 90-93.

[52] Kouidi E. Exercise training in dialysis patients: Why, when and how? Artif Organs 2002; 26(12) 1009-1113.

[53] Shiota E, Yamaoka K, Kawano O. Surgical treatments for orthopaedic complications in long-term haemodialysis patients - a reviw of 546 cases over the last 8 years. Fukuoka Igaku Zasshi 1998;89(9) 261-76.

[54] Brahee DD, Guebert GM, Virgin B. Dialysis-related spondyloarthropathy. J Manipulative Physiol Ther. 2001;24(2) 127-30.

[55] Perryman B, Harwood L. The role of physiotherapy in a hemodialysis unit. Nephrol Nurs J. 2004;31(2) 215-6.

[56] Juskowa J, Lewandowska M, Barłłomiejczyk I, Foroncewicz B, Korabiewska I, Niewczas M, Sierdziński J. Physical Rehabilitation and Risk of Atherosclerosis After Successful Kidney Transplantation. Transpl.Proc. 2006;38(1) 157-160.

[57] Korabiewska L, Lewandowska M, Juskowa J, Białoszewski D. Need for Rehabilitation in Renal Replacement Therapy Involving Alloveneic Kidney Tranplantation. Transpl.Proc. 2007;39(9) 2776-2777.

[58] Cristofolini T, Draibe S, Sesso R. Evaluation of Factors Associated with Chronic Low Back Pain in Hemodialysis Patients. Nephron Clin Pract 2008;108(4) c249-c255.

[59] Miller BW, Cress CL, Johnson ME, Nichols DH, Schnitzler MA. Exercise during hemodialysis decreases the use of antihypertensive medications. Am J Kidney Dis. 2002 ; $39(4)$ 828-833.

[60] Kutner NG, Brogan D, Fielding B. Employment status and ability to work among working-age chronic dialysis patients. Am J Nephrol 1991; 11(4) 334-340. 
[61] Parsons TL, Toffelmire EB, King-VanVlack CE. The effect of an exercise program during hemodialysis on dialysis efficacy, blood pressure and quality of life in endstage renal disease (ESRD) patiens. Clin Nephrol 2004; 61(4) 261-274.

[62] American College of Sports Medicine. Guidelines for exercise testing and prescription. Philadelphia: Lea \& Febinger; 1991.

[63] American College of Sport Medicine. Physical Fitness Testing In: ACSM's Guidelines for Exercise Testing and Prescription. 5th edition,Philadelphia: Williams\&Wilkins, $1995,49-78$.

[64] American Diabetes Association. Diabetes mellitus and Exercise. Diabetes Care 1997; 20: 1908-1912.

[65] Fletcher GF., Froehlicher, VF., Hartley LH., Haskell WL., Pollock ML. Exercise standards. A statement for health professionals from American Heart Association. Circulation 1990; 82: 2286-2322.

[66] Bullock RE, Amer HA, Simpson I, Ward MK, Hall RJ. Cardiac abnormalities and exercise intolerance in patients receiving renal replacement therapy. Br Med J 1984;289(6457)1479-1484.

[67] Painter P. The importace of exercise training in rehabilitation of patients with endstage renal disease. Am J Kidney Dis 1994; 24(1 Suppl 1) S2-9; discussion S31-2. Review.

[68] Goldberg AP, Geltman EM, Gavin JR 3rd, Carney RM, Hagberg JM, Delmez JA, Naumovich A, Oldfield MH, Harter HR. Exercise training reduces coronary risk and effectively rehabilitates hemodialysis patients. Nephron 1986; 42(4) 311-316.

[69] Ulmer HE, Griener H, Schüler HW, Schärer K. Cardiovascular impairment and physical working capacity in children with chronic renal failure. Acta Pediatr Scand 1978; 67(1) 43-48.

[70] Borg GA. Psychophysical bases of perceived exertion. Med Sci Sports Exerc 1982; 14(5) 377-387.

[71] Eston R, Connolly D. The use of ratings of perceived exertion for exercise prescription in patients receiving beta-blocker therapy. Sports Med. 1996;21(3) 176-90. Review.

[72] Painter P, Blagg CHR, Moore GE. Exercise for the Dialysis Patient. A Prescription Guide. Amgen Renal Advances. Medical Education Institute. 1995.

[73] Deligiannis A, Kouidi E, Tassoulas E, Gigis P, Tourkantonis A, Coats A. Cardiac effects of exercise rehabilitation in hemodialysis patients. Int J Cardiol 1999; 70(3) 253-266.

[74] Ridley J, Hoey K, Ballagh-Howes N. The exercise during hemodialysis program: report on a pilot study.CAANT 1999; 9(3) 20-26. 
[75] DePaul V, Moreland J, Eager T, Clase CM. The effectifness of aerobic and muscle strength training in patients receiving hemodialysis and EPO: a randomized controlled trial. Am J Kidney Dis 2002; 40(6) 1219-1229.

[76] Cappy CS, Jablonka J, Schroeder ET. The effects of exercise during hemodialysis on physical performance and nutrition assessment. J Renal Nutr 1999; 9(2) 63-70.

[77] Goldberg IJ. Lipoprotein metabolism in normal and uremic patients. Am J Kidney Dis 1993; 21(1) 87-90.

[78] Goldberg AP, Hagberg J, Delmez JA, Carney RM, McKevitt PM, Ehsani AA, Harter HR. The metabolic and psychological effect of exercise training in hemodialysis patients. Am J Clin Nutr 1980; 33(7) 1620-1628.

[79] Guyton H Jr (ed.). Fitness Book for People with Diabetes. American Diabetes Assn. Council on Exercise, 1994. In Painter P, Blagg CHR, Moore GE. Exercise for the Dialysis Patient. A Prescription Guide. Amgen Renal Advances. Medical Education Institute. 1995.

[80] No authors listed. Adequacy of dialysis and nutrition in continuous peritoneal dialysis: association with clinical outcomes. Canada-USA (CANUSA) Peritoneal Dialysis Study Group. J Am Soc Nephrol 1996;7(2) 198-207.

[81] Brodin E, Ljungman S, Hedberg M, Sunnerhagen KS. Physical activity, muscle performance and quality of life in patients treated with chronic peritoneal dialysis. Scand J Urol Nephrol 2001; 35(1) 71-78.

[82] Fahal IH, Bell GM, Bone JM, Edwards RH. Physiological abnormalities of sceletal muscle in dialysis patients. Nephrol Dial Ttransplant 1997; 12(1) 119-127.

[83] Jones CH, Newstead CG, Will EJ, Smye SW, Davison AM. Assessment of nutritional status in CAPD patients: serum albumine is not useful measure. Nephrol Dial Transplant 1997; 12(7) 1406-1413.

[84] Porter MM, Vandervoort AA, Lexell J. Aging of human muscle: structure, function and adaptability. Scand J Med Sci Sports 1995; 5(3) 129-142.

[85] Sugawara J, Miyachi M, Moreau KL, Dinenno FA, DeSouza CA, Tanaka H. Age-related reductions in appendicular sceletal muscle mass: association with habitual physical activity. Clin Physiol Funct Im, 2002, 22(3) 169-172.

[86] Campbell WW, Crim MC, Young VR, Joseph LJ, Evans WJ. Effects of resistance training and dietary protein intake on protein metabolism in older adults. Am J Physiol 1995; 268(6 Pt 1) E1143-153.

[87] Castaneda C, Gordon PL, Uhlin KL, Levey AS, Kehayias JJ, Dwyer JT, Fielding RA, Roubenoff R, Singh MF. Resistance training to counteract the catabolism of a lowprotein diet in patients with chronic renal insufficiency. A randomized control trial. Ann Intern Med 2001; 135(11) 965-976. 
[88] Sakkas GK, Sargeant AJ, Mercer TH, Ball D, Koufaki P, Karatzaferi C, Naish PF. Changes in muscle morphology in dialysis patients after six months of aerobic exercise training. Nephrol Dial Transplant 2003; 18(9) 1854- 1861.

[89] Koufaki P. The effect of erythropoietin therapy and exercise rehabilitation on the cardiorespiratory performance of patients with end-stage renal disease. $\mathrm{PhD}$ thesis. Manchester Metropolitan University; 2001.

[90] Koufaki P, Mercer TH, Naish PF. Effects of exercise training on aerobic and functional capacity of patients with end-stage renal disease. Clin Physiol Funct Imaging 2002; 22(2) 125-134.

[91] van Marken Lichtenbelt WD, Westerterp KR, Wouters L, Luijendijk SC. Validation of bioelectrical-impedance measurements as a method to estimate body-water compartments. Am J Clin Nutr 1994;60(2) 159-66.

[92] Barnea N, Drory Y, Iaina A, Lapidot C, Reisin E, Eliahou H, Kellermann JJ. Exercise tolerance in patients on chronic hemodialysis. Isr J Med Sci 1980; 16(1) 17-21.

[93] [93]Kong CH, Tattersall JE, Greenwood RN, Farrington K. The effect of exercise during haemodialysis on solute removal. Nephrol Dial Transplant 1999; 14(12) 2927-2931.

[94] O'connor AS, Leon JB, Sehgal AR. The relative ability of four different measures of hemodialysis dose. Am J Kidney Dis 2002;40(6) 1289-94.

[95] Man NK, et al. Long- term hemodialysis. Boston: Kluwer Academic Publishers; 1995.

[96] Ahonen RE. Light microscopic study of striated muscle in uremia. Acta neuropathol 1980; 49(1) 51-55.

[97] Durozard D, Pimmel P, Baretto S, Caillette A, Labeeuw M, Baverel G, Zech P. 31P NMR spectroscopy investigation of muscle metabolism in hemodialysis patients. Kidney Int 1993; 43(4) 885-92.

[98] Moore GE, Bertocci LA, Painter PL. 31P-magnetic resonance spectroscopy assessment of subnormal oxidative metabolism in sceletal muscle of renal failure patiens. J Clin Invest 1993; 91(2) 420-424.

[99] Kettner-Melsheimer A, Weiss M, Huber W. Physical work capacity in chronic renal disease. Int J Artif Organs 1987; 10(1) 23-30.

[100] Lange H. Adaptation und Rehabilitation unter chronisch intermittierender Dialysebehandlung und nach Nierentransplantation. Deutsche Forschungsgemeinschaft: Teilprojekt D4, 1976.

[101] Ramaswamy D, et al. Management of musculoskeletal complications in endstage renal disease: an update. Clin Rheumatol 2006;25(4) 440-2.

[102] Johansen KL. Exercise and dialysis. Scholarly Review. Hemodyalisis Int 2008;12: 290-300. 
[103] Lacerda G, Krummel T, Hirsch E. Neurologic presentations of renal diseases. Neurol Clin 2010;28(1): 45-59.

[104] Violan MA, Pomes T, Maldonado S, et al. Exercise capacity in hemodialysis and renal transplant patients. Transplant Proc. 2002;34(1) 417-8.

[105] Avesani C-M, Trolonge S, Del'eavak P, et al. Physical activity and energy expenditure in haemodialysis patients: aninternational survey. Nephrol Dial Transplant 2012;27: 2430-2434.

[106] Jhamb M, Weisbord SD, Steel JL, Unru M. Fatigue in Patients Receiving Maintenance Dialysis: A Review of Definitions, Measures, and Contributing Factors. Am J Kid Dis 2008;52(2) 353-365.

[107] Lobbedez T, Desbordes E, Joly F, et al.: Fatigue in elderly patients on dialysis. Nephrol Ther 2008;4(7): 584-9.

[108] Johansen KL. Neural and metabolic mechanisms of excessive muscle fatigue in maintenance hemodialysis patients. Am J Physiol Regul Integr Comp Physiol 2005;289 R805-R813.

[109] Gordon PL, Doyle JW, Johansen KL. Postdialysis fatigue is associated with sedentary behavior. Clin Nephrol 2011;75(5) 426-33.

[110] Lindsay RM, Heidenheim PA, Nesrallah G, et al. Minutes to recovery after a hemodialysis session: A simple health-related quality of life question that is reliable, valid, and sensitive to change. Clin J Am Soc Nephrol 2006;1 952-959.

[111] Delgado C, Johansen KL. Barriers to exercise participation among dialysis patients. Nephrol Dial Transplant 2012;27: 1152-1157.

[112] Moreno F, Sanz-Guajardo D, López-Gómez JM, et al. Increasing the hematocrit has a beneficial effect on quality of life and is safe in selected hemodialysis patients. Spanish Cooperative Renal Patients Quality of Life Study Group of the Spanish Society of Nephrology. J Am Soc Nephrol 2000;11(2) 335-342.

[113] Jones M, Ibels L, Schenkel B, Zagari M. Impact of epoetin alfa on clinical end points in patients with chronic renal failure: A meta-analysis. Kidney Int 2004;65 757-767.

[114] Storer TW. Endurance exercise training during haemodialysis improves strength, power, fatigability and physical performance in maintenance haemodialysis patients. Nephrol Dial Transplant 2005;20(7) 1429-1437.

[115] Yurtkuran M, Alp A, Yurtkuran M, Dilek K. A modified yoga-based exercise program in hemodialysis patients: A randomized controlled study. Complement Ther Med 2007;15(3) 164-171.

[116] Cho YC, Tsey SL. The effect of acupressure with massage on fatigue and depression in patients with end-stage renal disease. J Nurs Res. 2004;12(1) 51-9. 
[117] Jandová J. Vertebroviscerální vztahy. Doporučené postupy pro praktické lékaře (MZČR) [online] (CZ); 2001. http://www.cls.cz/dokumenty2/postupy/r113.rtf (Accessed 3 Fabruary 2007).

[118] Lewit K. Manipulační léčba v myoskeletální medicíně (CZ). Praha: Sdělovací technika; 2003.

[119] Rychlíková E. Manuální medicína: průvodce diagnostikou a léčbou vertebrogenních poruch (CZ). Praha: Maxdorf; 2004.

[120] Kiss E, Keusch G, Zanetti M, et al. Dialysis-Related Amyloidosis Revisited. Am J Roentgenol 2005;185(6) 1460-1467.

[121] SaitoA, Gejyo F. Current clinical aspects of dialysis-related amyloidosis in chronic dialysis patients. Ther Apher Dial 2006;10(4): 316-20.

[122] McDonald SP, Coates PD, Disney AP. Amyloid, advanced glycation end products, and dialysis related arthropathy. BMJ: Ann Rheum Dis 1998;57(4): 193-195.

[123] Niwa T. Dialysis-related amyloidosis: Pathogenesis focusing on AGE modification. Semin Dial 2001;14(2) 131-3.

[124] Cronin RE,, et al. Dialysis-related amyloidosis. Web site of UpToDate [online]; 2007. http://patients.uptodate.com/topic.aspo?file=dialysis/8834\&title=Dialysis+related tamyloidosis (Accessed 9 July 2007).

[125] Hurst NP, van den Berg R, Disney A, et al. Dialysis related arthropathy: a survey of 95 patients receiving chronic haemodialysis with special reference to beta 2 microglobulin related amyloidosis. Ann Rheum Dis 1989;48(5) 409-20.

[126] Henrich WL. Pathogenesis of renal osteodystrophy. Website of UpToDate [online]; 2007. http://patients.uptodate.com/topic.aspo?file=dialysis/44315 (Accessed 9 July 2007).

[127] Sudo H, Ito M, Abumi K. Long-term follow up of surgical outcomes in patients with cervical disorders undergoing hemodialysis. J Neurosurg Spine 2006;5(4) 313-9.

[128] Brown EA. Arnold IR, Gower PE. Dialysis arthropathy: complication of long term treatment with haemodialysis. Brit Med J 1986; 292(6514) 163-166.

[129] Kurer MH, Baillod RA, Madgwick JC. Musculoskeletal manifestations of amyloidosis. J Bone Joint Surg Br 1991;73(2) 271-6.

[130] Campistol JM, Bernard D, Papastoitsis G, et al. Polymerization of normal and intact $\beta 2$ microglobulin as the amyloidognenic protein in dialysis-amyloidosis. Kidney Int 1996;50(4) 1262-7.

[131] Leone A, Sundaram M, Cerase A, et al. Destructive spondyloarthropathy of the cervical spine in long-term hemodialyzed patients: a five-year clinical radiological prospective study. Skeletal Radiol 2001;30(8) 431-441. 
[132] Maruyama H, Gejyo F, Arakawa M. Clinical studies of destructive spondyloarthropathy in long term haemodialysis patients. Nephron 1992;61(1) 37-44.

[133] Davidson GS, Montanera WJ, Fleming JF, Gentili F. Amyloid destructive spondyloarthropathy causing cord compression: related to chronic renal failure and dialysis. Neurosurgery 1993;33(3) 519-522.

[134] Fukagawa M, Hamada Y, Nakanishi S, Tanaka M. The kidney and bone metabolism: Nephrologist's point of view. J Bone Miner Metab 2006;24(6): 434-438.

[135] Haas M. Renal osteodystrophy. Wien Med Wochenschr 2004;154(5-6) 107-118.

[136] Malluche HH, Mawad HW, Monier-Faugere MC. Renal osteodystrophy in the first decade of the new millennium: analysis of 630 bone biopsies in black and white patients. J Bone Miner Res. 2011 Jun;26(6) 1368-76. Erratum in: J Bone Miner Res. 2011 Nov;26(11) 2793.

[137] De Vernejoul MC, Kuntz D, Miravet L, et al.: Bone histmorphometry in hemodialysed patients. Metab Bone Dis Rel Res 1981;3(3) 175-179.

[138] Taal MV, Masud T, Green D, Cassidy MJ. Risk factors for reduced bone density in haemodialysis patients. Nephrol Dial Transplant 1999;14(8) 1922-1192.

[139] Sit D, Kadiroglu AK, Kayabasi H, et al. Relation ship between bone mineral density and biochemical markers of bone turnover in hemodialysis patients. Adv Ther 2007;24(5) 987-95.

[140] Urena P, Bernard-Poenaru O, Ostertag A, et al. Bone mineral density, biochemical markers and skeltal fractures in haemodialzsis patients. Nephrol Dial Transplant 2003;18(11) 2325-2331.

[141] Atsumi K, Kushida K, Yamazaki K, et al. Risk factors for vertebral fractures in renal osteodystrophy. Am J Kidney Dis 1999;33(2): 287-293.

[142] Shiota E, Tsuchiya K, Yamaoka K, Kawano O. Spontaneous major tendon ruptures in patients receiving long-term hemodialysis. Clin Orthop Relat Res 2002;(394) 236-42.

[143] Grzegorzewska AE, Mlot-Michalska M. Influence of age and sex on bone minerál density in dialysis patients. Adv Perit Dial 2007;23: 77-81.

[144] Watts NB, Adler RA, Bilezikian JP, Drake MT, Eastell R, Orwoll ES, Finkelstein JS. Osteoporosis in men: an Endocrine Society clinical practice guideline. J Clin Endocrinol Metab. 2012 Jun;97(6) 1802-22.

[145] Laaksonen S, Metsarinne K, Voipio-Pulkki LM, Falck B. Neurophysiologic parameters and symptoms in chronic renal failure. Muscle \& Nerve 2002; Jun;25(6) 884 -890.

[146] Aklouk I, Basic Kes V, Basic-Jukic N, et al. Uremic polyneuropathy. Acta Med Croatica $2004 ; 58(1)$ 59-61.

[147] Brautbar N. Skeletal myopathy in uremia. Abnormal energy metabolism. Kidney Int 1983;24(supl. 16) S81-S86. 
[148] Krishnan AV, Kiernan MC. Uremic neuropathy: clinical features and new pathophysiological insights. Muscle \& Nerve 2007;35(3) 273-90.

[149] Janda K, Stompór T, Gryz E, et al. (abstract) Evaluation of polyneuropahty severity in chronic renal failure patients on continuous ambulatory peritoneal dialysis or on maintenance hemodialysis. Przegl Lek 2007;64(6) 423-30.

[150] Klassen A, Di Iorio B, Guastaferro P, et al.: High-tone external muscle stimulation in end-stage renal disease: effects on symptomatic diabetic and uremic paripheral neuropathy. J Ren Nutr 2008;18(1) 46-51.

[151] Hupperts RM, Leunissen KM, van Hoff JP, Lodder J. Recovery of uremic neuropathy after renal transplantation. Clin Neurol Neurosurg 1990;92(1) 87-9.

[152] Innis J. Pain assessment and management for a dialysis patient with diabetic peripheral neuropathy. CANNT J 2006;16(2): 12-7, 20-6, quiz 18-9, 27-8.

[153] Ndip A, Lavery LA, Boulton AJ. Diabetic foot disease in people with advanced nephropathy and those on renal dialysis. Curr Diab Rep. 2010 Aug;10(4) 283-90. Review.

[154] Brouns R, De Deyn PP. Neurological complications in renal failure: a review. Clin Neurol Neurosurg 2004;107(1) 1-16.

[155] Staub F, Dombert T, Assmus H. Carpal tunnel syndrome in haemodialysis patients: analysis of clinical and electrophysiological findings in 268 patients (395 hands). Handchir Mikdrochir Plast Chir 2005;37(3) 150-7.

[156] Niemczyk S, Was M, Gomólka M. Carpal tunnel syndrome in dialysed patients - interdisciplinary experiences. Ortop Traumatol Rehabil 2004;6(3) 367-72.

[157] Namazi Z, Majd Z. Carpal tunnel syndrome in patients who are receiving long-term renal hemodialysis. Arch Orthop Trauma Surg 2007;127(8) 725-8.

[158] Kopec J, Gadek A, Drozdz M, et al. Carpal tunel syndrome in hemodialysis patients as a dialysis-related amyloidosis manifestation - incidence, risk factors and results of surgical treatment. Med Sci Monit 2011;17(9): CR505-9.

[159] Garcia S, Cofán F, Combalia A, et al. Compression of the ulnar nerve in Guyon's canal by uremic tumoral calcinosis. Arch Orthop Trauma Surg 2000;120(3-4) 228-30.

[160] Campistol JM. Uremic myopathy. Kidney International 2002;62(5): 1901-1913.

[161] Clyne N. Physical working capacity in uremic patients. Scand J Urol Nephrol 1996;30: 247-252.

[162] Kampeneers G, Noakes TD, Zyl-Smit R, et al. Skeletal muscle limits the exercise tolerance of renal transplant patients: Effects of a graded exercise training program. Am J Kidney Dis 1990;16(1) 57-65. 
[163] De-Bisschop E, Allein S, van Der Niepen P, et al. Effect of amino acid administration on uremic muscle metabolism: a 31P-spectroscopy study. Kidney Int 1997;51(4) 1182-7.

[164] Gordon PL, Sakkas GK, Doyle JW, et al. Relationship between vitamin D and muscle size and strength in patients on hemodialysis. J Ren Nutr 2007;17(6) 397-407.

[165] Noordzij, M., Boeschoten EW, Bos WJ, et al. Disturbed mineral metabolism is associated with muscle and skin complaints in a prospective cohort of dialysis patients. Nephrol Dial Transplant 2007;22(10): 2944-9.

[166] Riggs JE. Neurologic manifestations of fluid and elektrolyte disturbances. Neurol Clin 1989;7(3): 509-23.

[167] Adeniyi O, Agaba EL, King M, et al. Severe proximal myopathy in advanced renal failure. Diagnostis and management. Afr J Med Med Sci 2004;33(4) 385-8.

[168] Revaz, S., Theumann N, Lobrinus JA, et al. Leg pain due to bilateral focal recurrent myositis in a hemodialysis patient. Am J Kidney Dis 2005;45(1) e7-11.

[169] Anand S, Johansen KL, Grimes B, et al. Physical activity and self-reported symptoms of insomnia, restless legs syndrome, and depression: The comprehensive dialysis study. Hemodial Int. 2012 July 20. http://onlinelibrary.wiley.com/doi/10.1111/j.1542 4758.2012.00726.x/abstract;jsessionid=14B0A65E9D57D0F9FF6E20C9A2197C0E.d04t01?deniedAccessCustomisedMessage $=\&$ userIsAuthenticated=false (Accessed 27 July 2012).

[170] Molnar MZ, Novak M, Mucsi I. Management of restless legs syndrome in patients on dialysis. Drugs 2006;66(5) 607-24.

[171] Rijsman RM, De Weerd AW, Stam CJ, et al. Periodic limb movement disorder and restless legs syndrome in dialysis patients. Nephrology (Carlton) 2004;9(6) 353-61.

[172] Telarovic S, Relja M, Trkulja V. Restless legs syndrome in hemodialysis patients: association with calcium antagonists. A preliminary report. Eur Neurol 2007;58(3) $166-9$.

[173] Tuncel D, Orhan FO, Sayarlioglu H, et al. Restless legs syndrome in hemodialysis patients: association with depression and quality of life. Sleep Breath 2011;15(3) 311-5.

[174] Kvanagh D, Siddiqui S, Geddes CC. Restless legs syndrome in patients on dialysis. Am J Kidney Dis 2004;43(5) 763-71.

[175] Aukerman MM, Aukerman D, Bayard M, Tudiver F, Thorp L, Bailey B. Exercise and restless legs syndrome: a randomized controlled trial. J Am Board Fam Med. 2006 Sep-Oct;19(5) 487-93.

[176] Aminoff MJ. Neurology and general medicine. In: Raskin NH (ed.) Philadelphia: Churchill Livingstone; 1995. 
[177] Hung SC, Hung SH, Tarng Dc, et al.: Chorea induced by thiamine deficiency in hemodialysis patients. Am J Kidney Dis 2001;37(2) 426-30.

[178] Levy NB. Psychiatric aspects of renal care. In: Levine DZ. et al: Care of the Renal Patient. W.B. Saunders Company, 1991.

[179] Znojova M. Psychologické a sociální aspekty dialyzačního léčení. In: Sulková S. et al. Hemodialýza (CZ). Praha: Maxdorf, 2000.

[180] Curtin RB, Lowrie EG, DeOreo PB. Self-reported functional status: an important predictor of health outcomes among end-stage renal disease patients. Adv Ren Replace Ther. 1999;6(2) 133-40. Review.

[181] Morgenthal K. Ten years experience as a participant in a renal rehabilitation sport group. Clin Nephrol 2004;61(Suppl 1) 5.

[182] Stevens LA, Coresh J, Levey AS. CKD in the Elderly - Old Questions and New Challenges: World Kidney Day. Am J Kidney Dis 2008;51(3) 353-357.

[183] Coresh J, Selvin E, Stevens, LA, et al. Prevalence of chronic kidney disease in the United States. JAMA 2007;298(17) 2038-2047.

[184] Moreno F, Lopez Gomez JM, Sanz-Guajardo D, Jofre R, Valderrabano F. On behalf of the Spanish Cooperative Renal Patients Quality of Life Study Group: Quality of life in dialysis patients. A Spanish multicentre study. Nephrol Dial Transplant 1996; 11(suppl 2) 125-129.

[185] Kutner NG, Jasal SV. Quality of Life and Rehabilitation of Elderly Dialysis Patients. Seminars in dialysis 2002; 15(2) 107-112.

[186] Painter PL, Tomlanovich SL, Hector LA, et al. A randomized trial of exercise training following renal transplantation. Transplantation 2002; 74(1) 42-48.

[187] Spirduso, W.W. (1995): Physical Dimensions of Aging. Champaign: Human Kinetics, 1995.

[188] Kutner NG. Promoting functioning and well-being in older CKD patients: review of recent evidence. Int Urol Nephrol 2008; 40(4), 1151-1158.

[189] Musso CG, Macías Núněz JF. Feed-back between geriatric syndromes: general system theory in geriatrics. Int Urol Nephrol 2006; 38, 785-786.

[190] Gołębiowski T, Kusztal M, Weyde W, Dziubek W, Woźniewski M, Madziarska K, Krajewska M, Letachowicz K, Strempska B, Klinger M. A program of physical rehabilitation during hemodialysis sessions improves the fitness of dialysis patients. Kidney Blood Press Res 2012;35(4) 290-6.

[191] Painter P, Hanson P, Messer-Rehak D, Zimmermann SW, Glass NR. Exercise tolerance changes following renal transplantation. Am J Kidney Dis 1987;10(6) 452-456.

[192] Gallagher-Lepak S. Functional capacity and aktivity levels before and after renal transplantation. ANNA J. 1991;18(4) 378-82; discussion 382, 406. 
[193] Gross J, et al. Musculosceletal examination. Cambridge:Blackwell Science. 1996.

[194] American College of Sports Medicine. ACSM Position stand on Exercise and Physical activity for Older Adults. Medicine and Science in Sports and Exercise 1998;30(6) 992-1008.

[195] Rikli RE, Jones CJ. Senior Fitness Test Manual. Champaign, IL: Human Kinetics, 2001.

[196] Ragnarsdóttir M, Malmberg E, Strandberg E, Indridason OS. Increased physical fitness among patients following endurance training during haemodialysis. Scand J Urol Nephrol. 2012;46(1) 54-7.

[197] Bulckaen M, Capitanini A, Lange S, Caciula A, Giuntoli F, Cupisti A. Implementation of exercise training programs in a hemodialysis unit: effects on physical performance. J Nephrol. 2011;24(6) 790-797.

[198] Reboredo Mde M, Pinheiro Bdo V, Neder JA, Ávila MP, Araujo E Ribeiro ML, de Mendonça AF, de Mello MV, Bainha AC, Dondici Filho J, de Paula RB. Effects of aerobic training during hemodialysis on heart rate variability and left ventricular function in end-stage renal disease patients. J Bras Nefrol. 2010;32(4) 367-73.

[199] Mercer TH, Crawford C, Gleeson NP, Naish PF. Low-volume exercise rehabilitation improves functional capacity and self-reported functional status of dialysis patients. Am J Phys Med Rehabil. 2002;81(3) 162-167.

[200] Vurm V et al. Kvalita života u chronických onemocnění ve světle novějších modelů zdraví a nemoci. Kontakt (CZ) 2003; 5, 19-24.

[201] Dragomirecka E, Bartoňova J. WHOQOL-Bref a WHOQOL-100. Příručka pro uživatele české verze dotazníků kvality života Světové zdravotnické organizace, 1. vyd. (CZ), Praha: Psychiatrické centrum Praha, 2006.

[202] Ware EJ, et al.: The MOS 36-item short form health survey (SF-36) Conceptual framework and item selection. Medical Care (USA) 1992;30(6) 473-483.

[203] Hays RD, Kallich JD, Mapes DL, et al. Kidney Disease Quality of Life Short Form (KDQOL-SF), Version 1.3: A Manual for Use and Scoring. Santa Monica, CA: RAND, 1997.

[204] Jenkinson C, et al. Criterion validity and reliability of the SF-36 in a population sample. Quality of Life Research. Dordrecht 1994;3(1) 7-12.

[205] Jenkinson C, et al. The UK SF-36. An Analysis and Interpretation Manual. Oxford Health Services Research Unit, Great Britain, 1996.

[206] Mahrova A, Bunc V, Panacek V, Prajsova J. Exercise rehabilitation during hemodialysis - clinical experience. Aktuality v nefrologii (CZ) 2009; 15 (1) 16-24.

[207] Mahrova A, Prajsova J, Bunc V. Quality of life of haemodialysis patients in the Czech Republic as related to their physical activity. Kontakt (CZ) 2009; 2: 424-432. 
[208] Mahrova A, Jurova K, Prajsova J, Bunc V. The importance of physiotherapy in patients with chronic renal failure. Rehabilitace a fyzikální lékařství (CZ) 2009; 16 (4): 155-164.

[209] Mahrova A, Jurova K, Bunc V. Renal rehabilitation - the role of physical and exercise in chronic kidney disease and after renal transplantation. In: Proceedings of the XV International Congress on Nutrition and Metabolism in Renal Disease 2010, May 25-28, Lausanne, Switzerland. Bologna: Medimond International Proceedings, 2010; 5-11.

[210] Jurova K., Mahrova A. A Functional Investigation of The Movement System in Hemodialysis Patients. Leipziger Sportwissenschaftliche Beitraege 2010; 51(1) 131-137.

[211] Svagrova K, Mahrova, A, Bunc V, Stollova M, Teplan V. Physical Fitness in Patients Early after Renal Transplantation. Ceska Kinantropologie (CZ) 2011; 15(3): 200-207.

[212] Mahrova A, Svagrova K., Bunc V., Stollova M., Teplan V. Importance of Physical Activity in Elderly Renal Patients. Eur Rev Aging Phys Act 2010; 7(2) 73.

[213] Mahrova A,Svagrova K., Bunc V. Physical and Psychological Functions in Patients with the End-Stage Renal Disease. Kidney Res Clin Pract 2012; 31(2) 55.

[214] Mahrova A, Svagrova K, Bunc V, Teplan V, Stollova M. The Importance of an early Exercise and Nutrition Intervention among Renal Transplant Recipients. Kidney Res Clin Pract 2012; 31(2): A55.

[215] Kuta K: Kraft im Alternsverlauf. In: Meusel H et al: Bewegung, Sport und Gesundheit. Wiesbaden:Meyer\&Meyer, 1993.78-80.

[216] Gross JM, Fetto J, Supnick J. Vyšetření pohybového aparátu (CZ). Praha : Triton, 2005.

[217] Shephard RJ. Aging, physical activity and health. Champaign, IL: Human Kinetics, 1997.

[218] Fried LP, Ettinger WH, Lind B, Newman AB, Gardin J. Physical disability in older adults: A physiological approach. Journal of Clinical Epidemiology 1994;47(7) 747-760.

[219] Gill TM, Williams CS, Richardson ED, Tinetti ME. Impairtments in physical performance and cognitive status as predisposing factors for functional dependence among nondisabled older persons. J Gerontol A Biol Sci Med Sci.1996; 51(6) M283-M288.

[220] Guralnik JM, Ferrucci L, Simonsick EM, Salive ME, Wallace RB. Lower-extremity function in persons over the age of 70 years as a predictorof subsequent disability. $\mathrm{N}$ Engl J Med. 1995;332(9) 556-61.

[221] Heiwe S, Jacobson SH. Exercise training for adults with chronic kidney disease. Cochrane Database Syst Rev. 2011; Oct 5;(10):CD003236. 
[222] Painter PL, Nelson-Worel JN, Hill MM, Thornbery DR, Shelp WR, Harrington AR, Weinstein AB. Effects of exercise training during hemodialysis. Nephron. 1986;43(2) 87-92.

[223] Painter P. Implementing exercise: what do we know? Where do we go? Adv Chronic Kidney Dis. 2009;16(6) 536-44. Review.

[224] Kontos PC, Miller KL, Brooks D, et al. Factors influencing exercise participation by older adults requiring chronic hemodialysis: a qualitative study. Int Urol Nephrol 2007;39(4) 1303-1311.

[225] Goodman ED, Ballou MB. Perceived Barriers and Motivators to Exercise in Hemodialysis Patients. Neph Nurs J 2004;31(1) 23-29.

[226] Cheema BS, O'Sullivan AJ, Chan M, Patwardhan A, Kelly J, Gillin A, Fiatarone Singh MA. Progressive resistance training during haemodialysis: rationale and method of a randomized-controlled trial. Hemodial Int. 2006; 10(3) 303-310.

[227] Alter MJ. Science of flexibility. Champaign, IL: Human Kinetics, 1996.

[228] Svoboda L, Mahrová A. Pohyb jako součást léčby dialyzovaných a transplantovaných pacientů (CZ). Praha: Triton, 2009. 
